\title{
Los judíos de Ávila en vísperas de la expulsión
}

Serafín de TAPIA

Universidad de Salamanca

Cuando se escribe sobre los judíos españoles del último tercio del siglo XV, y sobre todo si se alude a cuestiones demográficas, casi resulta un tópico decir que antes de llegar a cualquier tipo de conclusiones es conveniente, e incluso necesario, incrementar la publicación de nueva documentación, pues la hasta ahora conocida resulta insuficiente.

\section{UN PADRÓN FISCAL Y SU CONTEXTO}

Con el fin de contribuir a cubrir algo de esta gran laguna documental, presento aquí un documento que, en mi opinión, tiene un gran interés. Se trata de un listado nominal de los cabezas de familia que en el año 1483 componían la aljama judía de la ciudad de Ávila'. La utilidad de este tipo de fuentes ha sido

\footnotetext{
1 Archivo del Ayuntamiento de Ávila, Sección Histórica (AAA-H), caja 1, leg. 76. En 1991 ya hice pública la existencia de este documento en S. DE TAPIA, La comunidad morisca de Ávila (Salamanca 1991) pág. 93. El documento no lo conocieron quienes en el pasado se interesaron por los judíos abulenses por encontrarse en una de las tres cajas que contenían papeles diversos y borradores de documentos referidos a las últimas décadas del siglo XV, que en su momento no fueron catalogadas por ninguno de los laboriosos archiveros municipales, y porque, cuando en los años 60 de este siglo se produjo el traslado de los fondos históricos del Ayuntamiento al Archivo Histórico Provincial de Ávila (AHPAv), por descuido tales cajas permanecieron en el -hasta hace poco- desorganizado archivo municipal. Recientemente este archivo del Ayuntamiento ha mejorado mucho y ahora está perfectamente accesible y atendido por su joven archivera, doña Sonsoles Guillén.
} 
encarecida por algunos autores, como el hebraísta David Romano, quien ha llegado a decir que el empleo de las listas nominales es «el sistema más seguro para calcular la población judía ${ }^{2}$.

En este caso se trata del repartimiento "quel Rey e la Reyna, nuestros señores, mandaron fazer enesa dicha çibdad de peones e bestias e hachas e palas para la Vega de Granada". Sus redactores fueron don Isaque Cohén y don Abraham Gago, veedores de la aljama, y don Abraham Sevillano, procurador de la aljama de los judíos de la ciudad de Ávila. Está fechado el 8 de febrero de 1483. Forma parte, por tanto, de la recluta que la Hermandad realizó de numerosas reatas de mulas con las que avituallar Alhama así como de impedimenta para facilitar el paso del ejército ${ }^{3}$. En este caso se asignan a la ciudad de Ávila 30 peones, 79 bestias, 2 hachas, 5 azadones y 5 palas que deben estar en Córdoba antes del 5 de abril.

Resulta esclarecedor el reparto que en el seno de la ciudad se hizo entre los tres grupos étnicos ${ }^{4}$ : los cristianos, que aproximadamente eran el 75 por ciento de los vecinos pecheros, aportaron el 33 por ciento; los judíos, cuyo número equivalía al 17 por cien, contribuían con el 44,3 por ciento del total; y finalmente a los moros (así son denominados siempre en la documentación), que demográficamente eran el 8 por ciento, se les asignó el 22,2 por ciento de lo repartido ${ }^{5}$. Esta desproporcionada distribución molestó a las aljamas de judíos y moros, pues hasta el momento los pecheros cristianos siempre habían aportado la mitad de la carga que correspondía a la ciudad; además, se daba la circunstancia de que los no cristianos estaban exentos de contribuir en los impuestos locales, "salvo en puentes e

2 D. Romano, "Prorrata de contribuyentes judíos de Jaca en 1377", Sefarad 42 (1982) págs. 3-39.

${ }^{3}$ M. A. LAdero Quesada, Castilla y la conquista del reino de Granada (Valladolid 1967).

${ }^{4}$ En esta y en las restantes ocasiones, se emplean los términos etnia, étnico, etc., en la acepción de la moderna antropología, es decir, como sinónimo de comunidad cultural y sin ningún tipo de carga racial.

${ }^{5}$ Los porcentajes demográficos, que no pretenden ser exactos, se han hecho suponiendo para estos años una población similar a la que recoge el Repartimiento del Servicio Real del año 1504, es decir, 1.133 vecinos -cabezas de familia - cristianos, excluidos los "nuevamente convertidos de moros"; cf. S. DE TAPIA, "Las fuentes demográficas y el potencial humano de Ávila en el siglo XVI", Cuadernos Abulenses 2 (1984) págs. 31-88: pág. 86. 
fuentes e cercas" ${ }^{6}$, por lo que tanto judíos como moros expresaron reiteradamente que, aunque por esta vez accedan a pagar estas cantidades, quieren que conste "que esto no avía de quedar ni quede por costumbre para adelante»?

Judíos y moros de Castilla soportaban en exclusiva el impuesto llamado "servicio y medio servicio", y desde 1482 la capitación especial del castellano de oro. Por su parte, los judíos de Ávila venían pagando desde 1384 una renta anual de $3.000 \mathrm{mrs}$. a la catedral ${ }^{8}$. A ello habría que añadir el préstamo forzoso para las necesidades de la guerra de Granada pedido por los Reyes en este mismo año de 1483, cuya cuantía en Ávila fue de 425.000 mrs. distribuidos de la siguiente manera: cristianos, 195.000; judíos, 130.000; y mudéjares, $100.000^{9}$.

Todo parece indicar que los Reyes Católicos habían decidido hacer recaer sobre los no cristianos el mayor peso posible de los enormes costos financieros de la guerra de Granada, al menos en estos primeros años, hasta que la aportación eclesiástica se convirtió en la fundamental ${ }^{10}$. Hay un detalle que refuerza la anterior aseveración: la disposición real que acompaña a la demanda a "algunas personas particulares» del elevado préstamo de 425.000 mrs. deja claro que son los Reyes -sus asesores, naturalmente- los que eligen "las personas que acordamos que nos hayan de prestar los dichos marevedíes"; en la nómina que sigue aparecen 13 cristianos, 9 moros y 75 judíos. Lo significativo es que los cristianos seleccionados son, creo que todos ellos,

${ }^{6}$ AHPAv, Ayunt. caja 1, leg. 43. En la nota 73 se indica cómo se distribuían en Ávila las obligaciones de vigilancia y de conservación de la muralla entre los distintos grupos étnicos y sociales.

7 Así se expresan el maestre Çale de la Calle y Mahomad de Málaga, diputados de la aljama de los moros (AAA-H, caja 1, leg. 7).

${ }^{8}$ Archivo Histórico Nacional (AHN), Clero, Ávila, catedral, pergs. carpeta 32, n 3, apud P. LeÓn Tello, Judíos de Ávila (Ávila 1963) págs. 36-41; a pesar de su antigüedad éste sigue siendo el trabajo básico para conocer a los judíos de Ávila, especialmente gracias a su Apéndice documental y su Inventario de documentos.

9 Archivo General de Simancas (AGS), Contaduría Mayor de Cuentas, $1^{\text {a }}$ época, leg. 45 , fol. 26. Este préstamo fue dado a conocer por M. A. LADERo, "Un préstamo de los judíos de Segovia y Ávila para la guerra de Granada, en el año 1483", Sefarad 35 (1975) págs. 151-157, quien analizó lo referido a la participación judía.

${ }^{10}$ Ladero Castilla págs. 203-213. Para una visión general de la conquista de Granada véase J. N. Hillgarth, Los Reyes Católicos, 1074-1516 (Barcelona 1984) cap. 2, quien proporciona una amplia bibliografía. 
ricos judeoconversos; en efecto, sin haber realizado una investigación exhaustiva, encuentro que 9 de los 13 cristianos se encuentran incluidos (ellos o familiares muy allegados) en la relación de los sambenitos de los quemados o procesados por judaizantes en la última década del siglo, a raíz del establecimiento de la Inquisición en Ávila hacia 1490, y que se conservaron en el Monasterio de Santo Tomás ${ }^{11}$.

¿Podemos aceptar que la Corona transmitió algún tipo de instrucción no escrita para que las élites locales cristiano-viejas seleccionaran de entre los cristianos precisamente a judeoconversos? Para responder a esta pregunta convendría saber si este fenómeno responde a una peculiaridad exclusiva de esta ciudad o si también se produjo en otros lugares con ocasión de este préstamo de 1483. En todo caso, estamos ante una clara manifestación de discriminación fiscal que favorecía a los cristianos viejos $^{12}$.

Obviamente los miembros de las minorías se resistían a estas prácticas, máxime si se tiene en cuenta que la intensidad de la exacción fiscal y de la discriminación tributaria era creciente. En 1487 los judíos se quejan de que en los repartimientos de la Hermandad se aplica desde 1483 un sistema distinto al que era habitual en la ciudad: en las derramas antiguas «cabían a las aljamas de los judíos y moros della la meytad de la dicha quan-

11 Además de Diego de Bernuy, que prestó 50.000 mrs. y sería quemado en 1492, aparecen Juan López de Dueñas, Diego Barrada, Álvaro Manuel, mercader, Alfonso Ximénez, hijo de Alfonso Ximénez, Juan de Lencera, Cristóbal Beato, hijo de Diego Beato, Juan Rodríguez Daza y Alonso de Toro. Los otros cuatro no incluidos entre los sambenitados son: La de Toribio Ordóñez, Ximén Muñoz, hijo de Juan Rodríguez, Juan Nieto y Juan Rodríguez de Logroño. La relación de sambenitos del monasterio de Santo Tomás (residencia de Torquemada y sede de la Inquisición por aquellos años) ha sido publicada en varias ocasiones: F. FITA, "Sambenitos en el templo de Santo Tomás de Ávila", Boletín de la Real Academia de la Historia 15 (1889) págs. 332-346; E. Ballesteros, Estudio histórico de Ávila y su territorio (Ávila 1896) págs. 371-381; y E. Ruiz Ayưcar, Sepulcros artísticos de Ávila (2a ed. Ávila 1985) págs. $258-268$.

12 La desigual participación en las cargas fiscales era general, lo único que cambiaba de unos lugares a otros y de unas a otras fechas era la magnitud de la discriminación; así, en la cercana Segovia, con una comunidad judía más rica que la de Ávila pero bastante menos numerosa, los hebreos aportaron en 1483 el 15,3 por cien ( 150.000 mrs.) y en 1486 el 31,2 por cien (28.125 mrs.) (AGS, Contaduría Mayor de Cuentas, $1^{a}$ época, leg. 45, fol. 26, y Registro General del Sello [RGS], 1486, fol. 162). 
tía e desto cabía a pagar a la aljama de los dichos judíos las dos partes e al aljama de los moros la una" ${ }^{13}$; en cambio el nuevo modelo de participación interétnica suponía, como hemos visto, que los cristianos colaboraban con un tercio y los dos tercios restantes corrían por cuenta de las minorías, las cuales tenían establecido entre sí desde antiguo una "concordia e concierto" por la que los judíos pagaban el doble que los moros.

El Concejo de la ciudad acordó que el nuevo sistema regiría para los repartimientos de la Hermandad y que el antiguo se aplicase a las derramas internas de la ciudad ${ }^{14}$.

\section{El NúMERo de los Judíos de Ávila}

Una vez encuadrado el documento en el contexto fiscal en el que se elaboró, entramos en su contenido. La comisión de tres notables judíos distribuyó a los vecinos (es decir, a los cabezas de familia o, más bien, unidades familiares) en 35 cuadrillas, cada una de las cuales debía aportar el valor de "un asno cargado de çevada y con sus costales y un terçio [de] peón". Es de suponer que las agrupaciones se hicieron de forma que la capacidad económica de sus componentes fuera en todas las cuadrillas similar.

La nómina incluye 264 vecinos y tiene la pretensión de no excluir a nadie ${ }^{15}$. Como es lógico en ella aparecen prácticamente todos los que participaron en el préstamo de ese mismo año de 1483'16; sólo 4 de los 70 nombres incluidos en la lista publicada por M. A. Ladero no los he identificado entre los de mi listado, pero eso no quiere decir que no estén, ya que bien pudiera ocurrir que cualquiera de los que los diputados judíos designan con sus apodos ("el Buey", "el Torraero", "Carrión", "Çingal», etc.) sea alguno de ellos (véase Apéndice: Listado 1).

Por fortuna la documentación disponible referida a aquellas fechas no se limita a estos dos listados. Se conservan dos volú-

${ }^{13}$ AAA-H, caja 1, leg. 87 (10-II-1487).

${ }^{14}$ AAA-H, caja 1, leg. 95 (2-VII-1488).

${ }^{15}$ En la relación de los mudéjares se registran 124 cabezas de familia (AAA-H, caja 1, leg. 76). Sobre los mudéjares puede verse mi libro Comunidad morisca caps. I y II. Lamentablemente no se conserva el padrón de los cristianos, sólo el detalle de lo que les correspondía pagar en cada partida (AAA-H, caja 1, leg. 75).

${ }^{16}$ Véase supra nota 9. 
menes de protocolos notariales del escribano Juan Rodríguez Daza, precisamente uno de los judeoconversos obligados a prestar dinero en 1483, cuyas escrituras corresponden a los años 1476-1477 y 1487-1488 ${ }^{17}$. En estos registros aparecen efectuando diversas operaciones 14 nuevos judíos abulenses, además de muchos de los recogidos en el padrón de 1483. Por otra parte, el simanquino Registro General del Sello aporta otros 3 nuevos nombres ${ }^{18}$. Por tanto, agrupando estos vecinos -junto con los 4 del préstamo de 1483 que no aparecen en el padrón- tendríamos otros 21 vecinos que se hallan documentados como viviendo en Ávila entre 1476 y 1488 , los cuales se podrían añadir a los 264 del padrón que aquí se comenta (véase Apéndice: Listado 2).

Es probable que alguno de estos 21 vecinos se corresponda con determinada persona de las incluidas en el padrón de los 264 , no sólo porque a veces se han usado apodos en vez de nombres y apellidos, sino porque en otras ocasiones al nombre sólo le acompaña el oficio (véanse los 11 últimos del Apéndice: Listado 1); por ejemplo, el "Abraham tintorero" del padrón pudiera ser el Abraham Moshod (Masod o Masot, según la grafía abulense) del préstamo. O simplemente, que en el caso de los que aparecen antes de 1483 sin constar en el padrón de ese año, hubieran muerto o emigrado antes de esta última fecha, y que los 13 que aparecen entre 1487 y 1488 aún fueran menores de edad cuando se realizó el padrón. No obstante, ni esta última explicación ni las anteriores valen para el caso del financiero Isaque Tamaño, que inexplicablemente no se incluye en el padrón a pesar de estar documentada su vecindad en Ávila

17 AHPAv, Protocolos (Prot.) 421 y 420 (de éste sólo los fols. 21-88 y 259-307). Recientemente han publicado el catálogo de estos registros S. JIMÉNEZ y A. Redondo, Catálogo de Protocolos Notariales del Archivo Histórico Provincial de Ávila, (siglo XV), 2 vols. (Ávila 1992). Romano "Prorrata" pág. 11 subraya la importancia de utilizar la documentación de carácter local, en especial los protocolos notariales.

${ }_{18}$ Dentro de la encomiable serie de Fuentes Históricas Abulenses (núms. 18 a 22), se han publicado de momento cinco volúmenes acerca de la Documentación Medieval Abulense en el Registro General del Sello (Ávila 1993). Los autores de cada uno de los tomos son, respectivamente, J. L. Martín Rodriguez, C. Luis lópez, T. Sobrino Chomón, G. del Ser Quijano y B. Casado Quintanilla. A partir de ahora las referencias al Registro General del Sello proceden siempre de dicha serie. Respecto al códice 412 B del Archivo Histórico Nacional, véase LEÓN TEllo Ávila docs. 353 y 345. 
tanto antes como después de $1483{ }^{19}$. ¿Estaría ausente algún tiempo?

Sea como fuere, el número de familias judías de Ávila en 1483 oscilaría entre un mínimo de 264 y un máximo de 285. Estas cifras conceden a esta comunidad la primacía demográfica entre las aljamas de la Corona de Castilla cuyo volumen de población se conoce con precisión ${ }^{20}$.

Es casi seguro que los datos proporcionados por los numerosos repartimientos fiscales de 1472 a $1491^{21}$, que sitúan a Ávila siempre en uno de los tres primeros puestos por el montante de su aportación económica, no hagan más que reflejar su pujanza demográfica. Hubo tres ciudades que la superaron en alguna ocasión: Murcia, Toledo y Segovia. Ahora bien, las dos últimas acumulaban las aportaciones tributarias del núcleo urbano y de importantes juderías de su distrito (Gálvez, Alcázar de Consuegra, Ventas de Peña Aguilera y Torrijos en el caso de Toledo; y Turégano -con Chinchón en algún año- en el de Segovia). Se sabe que en el último tercio del siglo XV los judíos de ambas ciudades habían disminuido mucho, aunque vivieran en ellas algunos individuos acaudalados e influyentes; eran ciudades de muchos conversos y pocos judíos ${ }^{22}$. Respecto a Murcia las más recientes monografías locales proporcionan para estas fechas cifras que oscilan entre 150 y 141 vecinos con tendencia a disminuir ${ }^{23}$.

19 En 1480 es uno de los representantes de la aljama de Ávila en un pleito contra un antiguo corregidor de la ciudad (AGS, RGS, 14-IX-1480, fol. 199) y en 1489 se dirige a los Reyes, como vecino de Ávila, pidiéndoles el favor de que ordenen al corregidor que prohíba a los receptores de empréstitos apremiarle (Documentación vol. V págs. 95-96).

${ }^{20}$ Véase una amplia bibliografía, actualizada por J. L. LACAVE, en Y. BAER, Historia de los judios en la España cristiana (Madrid 1981) págs: 762-763.

${ }^{21}$ L. Suárez Ferinández, Documentos acerca de la expulsión de los judios (Valladolid 1964) págs. 63-72; F. CANTERA y C. CARRETE, "Los repartimientos de Rabí Jaco Aben Núñes". Sefarad 31 (1971) págs. 213-247; y M. A. LADERo, "Las juderías de Castilla según algunos 'servicios' fiscales del siglo XV", Sefarad 31 (1971) págs. 249-264.

22 Véase para el caso toledano C. CARrete, "Tributación económica de las comunidades judías toledanas", en Actas del IV Congreso Internacional Encuentro de las Tres Culturas (Toledo 1988) págs. 19-34. Una síntesis actualizada de lo que se conoce de las diversas comunidades, puede verse en $\mathbf{J}$. L. LACAVE, Juderías y sinagogas españolas (Madrid 1992).

${ }^{23}$ Véase L. Rubio García, Los judios de Murcia en la Baja Edad Media (1350-1500) (Murcia 1992) págs. 133-135. 
En 1485 otras cuatro poblaciones superaron los 300 castellanos aportados por Ávila: Zamora, Trujillo, Ocaña y Almazán, pero, excepto en esta última que habitualmente pagaba menos que Ávila, siempre se trataba de unas cantidades resultantes de agrupar varias juderías del distrito. Así pues, mientras no aparezca nueva documentación que demuestre lo contrario, puede afirmarse que la aljama de Ávila era la más numerosa de la Corona de Castilla, confirmándose lo que $\mathrm{H}$. Kamen había adelantado: que Ávila fue una excepción en la general decadencia de las aljamas judías españolas ${ }^{24}$.

Hasta 1768 los recuentos demográficos en los países hispánicos emplean siempre la unidad "vecino", concepto fiscal que, aunque normalmente coincide con una familia, también se usa para designar hogares unipersonales (viudos/as sin hijos, solteros/as mayores); por otra parte, era habitual que parientes y criados convivieran, junto con el núcleo familiar, bajo el mismo techo. Es, por tanto, un problema complejo encontrar un coeficiente riguroso para transformar la unidad vecino en el actual término unívoco de habitante. No obstante, la demografía histórica ha desarrollado técnicas que permiten alcanzar un alto nivel de precisión en la determinación de dicho coeficiente ${ }^{25}$.

Estudiando el caso de la ciudad de Ávila hallé que a finales del siglo XVI la cifra de 3,7 era el coeficiente que procedía aplicar para convertir en habitantes, en individuos, el número expresado en vecinos ${ }^{26}$. No me consta ningún dato que me induzca a pensar que los judíos abulenses tenían pautas de comportamiento demográfico diferentes a las de sus paisanos cristianos.

${ }^{24} \mathrm{H}$. Kamen, "La expulsión: finalidad y consecuencias", en Los judios de España, ed. E. Kedourie (Barcelona 1992) págs. 74-96.

${ }_{25}$ Véase, por ejemplo, B. VINCENT, "Récents travaux de démographie historique en Espagne (XIV-XVIII siècles)", Annales de Démographie Historique (1977) págs. 463-491.

${ }^{26}$ S. DE TAPIA "Fuentes demográficas" págs. 51-53. En estos cálculos fueron excluidos los numerosos religiosos, lo que contribuye a eliminar un factor de diferenciación demográfica entre cristianos y judíos. El coeficiente de Ávila no era muy diferente del calculado para otras ciudades de esta zona del país: 3,75 en Segovia; 3,2 en Salamanca; 3,78 en Cáceres; etc. Cf. respectivamente A. García SAnz, Desarrollo y crisis del Antiguo Régimen en Castilla la Vieja: Economia y Sociedad en tierras de Segovia, 1500-1814 (Madrid 1977) pág. 43; M. Fernández Álvarez, "La demografía de Salamanca a través de los fondos parroquiales", en Homenaje al doctor J. Reglá (Valencia 1975) vol. I pág. 353; y A. Rodriguez Sánchez, Cáceres: población y comportamientos demográficos en el siglo XVI (Cáceres 1977) págs. 224-225. 
Por otra parte, se sabe que los cambios en estos comportamientos se realizan muy lentamente a lo largo del tiempo, por lo que es presumible que lo que valía para 1594 (fecha sobre la que efectué los cálculos) también sirviera para un siglo antes. Por tanto -aceptando como bueno el coeficiente 3,7- la población judía de la ciudad de Ávila en 1483 oscilaría entre 977 y 1.058 personas ${ }^{27}$.

\section{ESTRUCTURA OCUPACIONAL}

Además del volumen del grupo judío de Ávila, el listado de 1483 nos aporta algunos datos sobre un aspecto de gran interés y del que en muy pocos lugares se dispone de información contrastada: se trata de los oficios a que se dedicaban los cabezas de familia de nuestra minoría.

Quienes elaboraban los padrones fiscales carecían de preocupaciones estadísticas o sociológicas; únicamente buscaban confeccionar una lista que facilitara el trabajo de los recaudadores. Por ello sólo indican el oficio de los diversos individuos cuando es imprescindible, bien en caso de homonimia completa (nombre y apellido), bien por ser conocido sobre todo por el trabajo al que se dedicaba. Por desgracia para nuestro objetivo, a veces la indicación del oficio ha sido sustituida por las relaciones familiares. Así pues, sólo se nos indica el oficio de 24 personas, a las que habría que añadir otras 9 calificadas como rabíes.

Ahora bien, el resto de la documentación utilizada -sobre todo los protocolos notariales- nos ha permitido conocer la ocupación de 40 individuos diferentes de los que aparecen con oficio en el padrón. Es decir, que entre una información y otra sabemos el oficio de un total de 73 personas, más de la cuarta parte del total de cabezas de familia de la aljama local ${ }^{28}$.

Por proceder parte de la información de una fuente de las características de los protocolos notariales, es casi seguro que la tipología profesional de esta muestra no sea absolutamente

${ }^{27}$ Se confirma así la suposición de Ladero "Préstamo" pág. 152 de que la cifra de 3.000 judíos expulsados de Ávila, propuesta por P. León Tello, es demasiado elevada.

${ }^{28} \mathrm{Me}$ ha parecido que podía considerar como aceptable la información sobre profesiones aportada por documentación suficientemente cercana al año 1483 . concretamente la horquilla cronológica que va desde 1476 a 1488. 
proporcional a la que en realidad existía en la aljama abulense: estarán más representados quienes por dedicarse a las labores cualificadas requerían el concurso del escribano (el prototipo son los prestamistas), mientras que habrá una menor representación de quienes no lo necesitaban habitualmente (artesanos, asalariados, agricultores, etc.). De todas formas en aquellas épocas, y al contrario de lo que hoy ocurre, estaba muy generalizada entre todos los sectores sociales la práctica de acudir a una escribanía, por ello me parece interesante dar a conocer la estructura ocupacional que resulta de la información disponible (Cuadro 1).

Se confirma lo que se conoce de otros núcleos urbanos de la Corona de Castilla:

- que el grueso de los judíos eran artesanos (61,6\%);

- que no eran pocos los que desarrollaban empleos que en nuestra terminología actual se podrían calificar como del sector servicios $(38,3 \%)$;

- que ni agricultura ni ganadería eran actividades frecuentes entre ellos.

\section{Industria}

Dentro del sector artesanal o industrial, el subsector con más efectivos es el del cuero/calzado. Nada menos que el 28,8 por ciento de los de oficio conocido trabajaba en las diversas labores del cuero: hay odreros, zapateros, zurradores, chapineros y especialmente 14 curtidores. Esta circunstancia no es específica de la comunidad judía abulense; también se ha detectado en otros lugares de Castilla, como Salamanca ${ }^{29}$, Palencia ${ }^{30}$ y Ciudad Rodrigo ${ }^{31}$, o de la Corona de Aragón, como Zaragoza ${ }^{32}$ y Hues-

${ }^{29}$ M. ${ }^{a}$ F. García Casar, El pasado judío de Salamanca (Salamanca 1987) págs. 14 y 113 .

${ }^{30}$ P. León Tello, Los judios de Palencia (Palencia s.d.) pág. 26. .

31 F. Sierro Malmierca, Judios, moriscos e Inquisición en Ciudad Rodrigo (Salamanca 1990) pág. 30; y también M. ${ }^{2}$ F. García CASAR, El pasado judio de Ciudad Rodrigo, vol. VI de la serie Fontes Iudaeorum Regni Castellae (Salamanca 1992).

${ }^{32}$ A. Blasco Martínez, "Los judíos de Zaragoza en el siglo XIV: su evolución social", en Minorites et marginaux en Espagne et dans le midi de la France (VIIe-XVIIle siècles) (Paris 1986) págs. 177-202. 
Cuadro 1

Estructura ocupacional de los diversos grupos étnicos

\begin{tabular}{|c|c|c|c|c|c|c|}
\hline \multirow{8}{*}{$\begin{array}{l}\text { Industria } \\
\text { manufactura textil } \\
\text { confección textil } \\
\text { artesanía del metal } \\
\text { construcción/carpintería } \\
\text { cuero/calzado } \\
\text { industrias artísticas } \\
\text { industrias varias }\end{array}$} & \multicolumn{2}{|c|}{$\begin{array}{l}\text { cristianos }^{a} \\
(\text { año 1517) }\end{array}$} & \multicolumn{2}{|c|}{$\begin{array}{c}\text { judíos } \\
\text { (año 1483) } \\
\end{array}$} & \multicolumn{2}{|c|}{$\begin{array}{r}\operatorname{moriscos}^{b} \\
(\text { año 1503) } \\
\end{array}$} \\
\hline & 49 & $14,1 \%^{c}$ & 6 & $8,2 \%$ & 2 & $2,3 \%$ \\
\hline & 38 & $10,9 \%$ & 10 & $13,7 \%$ & - & - \\
\hline & 17 & $4,9 \%$ & 5 & $6,6 \%$ & 25 & $28,7 \%$ \\
\hline & 36 & $10,4 \%$ & - & - & 17 & $19,5 \%$ \\
\hline & 55 & $15,8 \%$ & 21 & $28,8 \%$ & 3 & $3,4 \%$ \\
\hline & 15 & $4,3 \%$ & 1 & $1,4 \%$ & - & - \\
\hline & 25 & $7,2 \%$ & 2 & $2,7 \%$ & 2 & $2,3 \%$ \\
\hline total & 3 & $67,1 \%$ & 45 & $61,6 \%$ & 49 & $56,3 \%$ \\
\hline
\end{tabular}

Servicios

\begin{tabular}{|c|c|c|c|c|c|c|}
\hline alimentación & 19 & $5,5 \%$ & 3 & $4,1 \%$ & 9 & $10,3 \%$ \\
\hline comercio/transp. & 17 & $4,9 \%$ & - & - & 26 & $29,9 \%$ \\
\hline burocracia & 4 & $1,1 \%$ & 1 & $1,4 \%$ & - & - \\
\hline finanzas & - & - & 12 & $16,4 \%$ & - & - \\
\hline ervicio domést. & 27 & $7,8 \%$ & - & - & - & - \\
\hline ervicio sanitario & 9 & $2,6 \%$ & 3 & $4,1 \%$ & - & - \\
\hline rvicio religioso & 3 & $0,9 \%$ & 8 & $11,0 \%$ & - & - \\
\hline rvicios varios & 22 & $6,3 \%$ & 1 & $1,0 \%$ & - & - \\
\hline total & 101 & $29,1 \%$ & 28 & $38,3 \%$ & 35 & $40,2 \%$ \\
\hline ricultura/ganadería & 13 & $3,7 \%$ & - & - & 3 & $3,4 \%$ \\
\hline $\begin{array}{l}\text { tal población } \\
\text { tal vecinos }\end{array}$ & $\begin{array}{r}347 \\
1.366\end{array}$ & $25,4 \%$ & $\begin{array}{r}73 \\
264\end{array}$ & $27,6 \%$ & $\begin{array}{r}87 \\
161\end{array}$ & $54,0 \%$ \\
\hline
\end{tabular}

a Aquí se agrupa el conjunto de vecinos pecheros, excluidos los moriscos, aunque éstos eran formalmente cristianos. De entre los padrones que ofrecen un volumen de población pechera plausible, el de 1517 es el más cercano a 1483.

b Los mudéjares de Ávila se convirtieron en masa en 1502 al cristianismo, pasando al status de morisco.

${ }^{c} \mathrm{El}$ porcentaje se refiere en los tres casos a la población activa de la que se conoce el oficio.

Uso las siguientes fuentes. Para los judíos, las arriba comentadas: el padrón de 1483 (AAA-H, caja 1, leg. 76) y los dos volúmenes de protocolos notariales conservados (AHPAv, Prot. 421 y 420). En el caso de los cristianos, el padrón nominal de vecinos pecheros (no incluye, por tanto, hidalgos y clérigos) para repartir el pago del Servicio Real y para recaudar 20.000 mrs. para pleitos (AHPAv, Ayunt. caja 59, leg. 6/24). Y para los moriscos, el padrón nominal para repartir $40.000 \mathrm{mrs}$. (ibid., caja 58, leg. 6/4), cuya información sobre profesiones se ha completado con la procedente de muy diversas fuentes. 
$\mathrm{ca}^{33}$. Así pues, se refuerza la afirmación de J. L. Lacave de que las labores relacionadas con las tenerías eran en bastantes poblaciones típicas de judíos ${ }^{34}$. Se trataba de una actividad especialmente desagradable a causa de la mucha humedad y malos olores que acompañaban a los trabajos de preparación del cuero. Por ello y porque necesitaba abundante agua, en casi todos los lugares existía un barrio especializado en esta actividad (llamado "la baldresería" o "de las tenerías"), situado en los arrabales y no lejos del río. Significativamente en varias ciudades castellanas esta zona suele coincidir con el lugar ocupado por los judíos, sobre todo a partir del encerramiento de 1480 .

Como ocurría en Segovia, los judíos abulenses tradicionalmente habían vivido en cualquier parte de la ciudad, sobre todo en el centro ${ }^{35}$; por eso cuando se vieron obligados a acomodarse en un espacio delimitado, pequeño e insano, se produjeron quejas. A través de ellas sabemos que en estos años finales del siglo XV se estaba incrementando la dedicación de los judíos a los curtidos. Efectivamente, cuando en 1482 se estableció el emplazamiento de la nueva judería, se ordenó que "çiertas tenerías e noques e pelambres e otras cosas de cortidumbre que en la dicha judería estaban ... las sacasen de la judería e çibdad e las pasasen a las tenerías que estavan a par del río".

Sin embargo, los curtidores judíos no obedecieron, por lo que los recién llegados se quejan de que sus correligionarios «no lo han querido ni quieren sacar los dichos hedefiçios e tenerías, mas dis que de cada día labran más en ellas e hedefican en ellas nuevas tenerías e derraman la tinta por las calles de la dicha judería e dis que las gentes no pueden conportar los malos olores ...n" ${ }^{36}$.

33 J. L. LACAVE, "Las juderías aragonesas al terminar el reinado de Fernando I", Sefarad 39 (1979), págs. 209-224: pág. 221.

${ }^{34}$ "La sociedad judía y la aljama en la época de la expulsión", en $\mathbf{H}$. Méchoulan (ed.), Los judíos de España: Historia de una diáspora (1492-1992) (Madrid 1993) págs. 31-37: pág. 32.

${ }^{35}$ Así queda reflejado en un documento de 1303 que recoge los bienes inmuebles pertenecientes al Cabildo catedralicio y que cuando describe las propiedades en la ciudad, enumera las casas así como sus inquilinos; "Becerro de visitaciones de casas y heredades" AHN, Clero, códice 484 B, publ. por A. Barrios García, Documentación medieval de la catedral de Ávila (Salamanca 1981). Información detallada sobre dónde habitaron los judíos de Ávila en los siglos XIV y XV la proporciona J. Belmonte Díaz, Judíos e Inquisición en Ávila (Âvila 1989) págs. 51-56 y 80-90.

${ }^{36}$ AHPAv, Ayunt. caja 1, leg. 55 (publ. por León Tello Ávila págs. 73-74). 
En las Ordenanzas de Ávila de 1487, elaboradas sin la presencia de representantes judíos y moros a pesar de las importantes funciones que desempeñaban en la economía urbana ${ }^{37}$, se hace referencia a este subsector productivo: en la ley 83 se establece la prohibición de sacar a vender fuera de la ciudad y de su tierra el calzado hecho en Ávila ${ }^{38}$. ¿Cómo interpretar esta disposición?, ¿se pretendía perjudicar a los judíos limitando su mercado? No lo creo, entre otras razones porque este tipo de trabajo no interesaba a los cristianos. Quizá esta medida estuviera más relacionada con la concepción premercantilista propia del medievo: había que asegurar el abastecimiento de la ciudad y el mantenimiento moderado de los precios. La escasa capacidad de presión de los curtidores, casi todos judíos, ante el Concejo haría el resto. En todo caso, se trata de una medida que perjudicaba a la profesión más frecuente entre los judíos de Ávila.

El otro subsector artesanal preferido por los individuos de nuestra minoría era el relacionado con el textil. En esta actividad conviene distinguir entre las labores relativas a las distintas fases de la producción de los paños (tejer, tundir, cardar, teñir, etc.) y los de la confección. Esta última, menos estrictamente industrial que la primera, era la más habitual: 6 sastres y 3 jubeteros, más 1 zurcidor suponen el 13,7 por ciento de los activos. Como ocurría con los curtidores, también en otros lugares era típica la figura del sastre judío. En mi opinión resulta significativa la limitada participación de los artesanos judíos en el subsector laboral más importante de la ciudad, la manufactura textil: ni un solo tejedor está documentado. Sólo el tinte cuenta con una representación aceptable, a pesar de no ser una especialidad de la industria textil local ${ }^{39}$.

37 "... el trabto e conversación de la dicha çibdad está en moros e judíos" decía el Concejo en un informe enviado al rey en 1488 (AGS, RGS, 28-V-1488, fol. 8; publ. por León Tello Ávila pág. 79). Acerca de cómo se elaboró este importante instrumento de regulación de la actividad económica de la ciudad, véase J. Gautier Dalché, "Les processus de décision dans un gouvernement urbain selon les Ordonnances d'Ávila (1487)", en La Ciudad Hispánica durante los siglos XIII al XVI (Madrid 1985) vol. I págs. 507-520.

38 J. M. ${ }^{a}$ Monsalvo, Ordenanzas medievales de Ávila y su tierra (Ávila 1990) pág. 131.

${ }^{39}$ Por ejemplo, en el padrón del servicio de 1514 , en el que aparecen todos los vecinos pecheros cabezas de familia, únicamente se cuentan 7 tintoreros (AHPAv, Ayunt. caja 59, leg. 6/24). 
Los 5 herreros, 1 albardero, 1 cerero y 1 batidor de oro ${ }^{40}$ constituyen el resto de los componentes del sector industrial, hasta completar la nómina de los 45 recogidos en el Cuadro 1.

\section{Servicios}

El sector terciario acumula el 38,3 por ciento de los activos, si bien hay que considerar esta cifra con cierta prevención, ya que los dos subsectores mejor representados, el de las finanzas y el de los servicios religiosos, sólo relativamente pueden ser incluidos en este bloque y no en otro. Estas palabras requieren una explicación. Las personas que he identificado realizando actividades crediticias o de arrendamiento de impuestos o rentas y que he agrupado como dedicadas a las finanzas es sabido que eran individuos acomodados, que normalmente practicaban aquellas funciones compaginándolas con su ocupación habitual. Otro tanto puede decirse de los rabinos, quienes a pesar del poder moral que tenían en el seno de la aljama, desempeñaban ocupaciones convencionales dentro del sector de los servicios: en el caso de Ávila aparece un rabino médico y otros dos que son recaudadores de impuestos, y en 1438, fuera de nuestro ámbito cronológico, uno que es librero ${ }^{41}$; a éstos les asigno al grupo que les corresponde. Por tanto, los 8 rabinos del Cuadro 1 son aquellos de los que no tengo otra indicación laboral. Incluso el rabino que probablemente mayor dedicación tenía a los asuntos religiosos, Abraham Abenaçay, que era el cantor de la aljama, aparece en 1488 vendiendo vino a los mesoneros ${ }^{42}$.

Volviendo al subsector de las finanzas, conviene dejar claro que quienes se dedicaban en Ávila a ello no eran grandes finan-

${ }^{40}$ En 1465 Mosé Dono, batidor de oro, se compromete con el pintor Sansón Florentín a facilitarle todo el oro y plata que necesite para las tablas que éste realiza en la catedral (AHN, Clero, códice 451 B, fol. 3; apud León Tello Ávila pág. 141).

${ }_{41}$ Se trata de rabí Culema, quien tenía su librería en la calle principal de la judería, hoy llamada de Santo Domingo (AHN, códice 389 B, fol. 163; apud León Tello Ávila pág. 130). En nuestro listado de 1483 hay otro rabí Çulemán [Daça], que no creo sea el mismo de 1438. Estos libreros se dedicaban a hacer copias manuscritas de libros. En otros lugares de España y de Europa también se ha documentado esta actividad de los rabíes; cf. E. Martinez LIÉBana, Los judíos de Sahagún en la transición del siglo XIV al XV (Valladolid 1993) pág. 40, y I. Abrahams, Jewish Life en the Middle Ages (New York 1969) págs. 340 y 353-354.

${ }^{42}$ AHPAv, Prot. 420 , fol. $290 \mathrm{v}$. 
cieros de la Corona de Castilla y ni siquiera del territorio de la meseta norte castellana. Resulta significativo que en la relación de arrendadores judíos de rentas reales de 1481, 1487, 1488 y 1491 , publicada a partir de los datos de $\mathrm{Y}$. Baer ${ }^{43}$, no aparezca ninguno de Ávila, mientras que las rentas de esta ciudad y su distrito frecuentemente son arrendadas por judíos de las ciudades limítrofes: Toledo, Salamanca y Segovia.

No obstante, nueva documentación aparecida nos revela que había algunos financieros entre los judíos de Ávila que a veces trabajaban para la Corona, probablemente integrados como miembros no principales en alguna de las grandes redes de arrendadores, factores, recaudadores y fiadores judíos o conversos que operaban en todo el reino. Los 5 individuos identificados en estas labores mantenían entre sí vínculos familiares o profesionales. Uno de ellos es Isaque Tamaño, quien, como ya hemos visto, no aparece en el padrón a pesar de estar comprobado que vive en Ávila al menos hasta 1493, siendo uno de los pocos que prefirió convertirse ${ }^{44}$. Este personaje recauda empréstitos reales en Ávila y su tierra en 1475 y 1476; tal actividad le ocasionaría enojosos pleitos, siendo acusado en 1480 del delito de cercenar moneda ${ }^{45}$.

Un allegado de Isaque Tamaño, Mosé Tamaño, era el más acaudalado y, por ende, poderoso de los judíos abulenses; en 1468 la princesa heredera Isabel le había nombrado juez mayor de la aljama de los judíos de Ávila ${ }^{46}$. En 1480 adelantó al Concejo de la ciudad la cantidad que se necesitaba para pagar a las tropas que se habían asignado a Ávila para el cerco de Castronuño y Cantalapiedra ${ }^{47}$. Como administrador de Mosé Tamaño aparece Abraham Melamed, probablemente el más activo de los negociantes de la aljama: en numerosas ocasiones arrienda alcabalas, sobre todo de los paños, y hace todo tipo de préstamos y nego-

${ }^{43}$ M. A. Ladero, "Los judíos castellanos del siglo XV en el arrendamiento de impuestos reales", Cuadernos de Historia 6 (1975) págs. 417-439.

${ }^{44}$ AGS, RGS, 12-XII-1493, fol. 84.

45 AHPAv, Prot. 421, fol. 65; también AGS, RGS, 2-IX-1479, fol. 66, doc. 1.969 y 23-II-1489, fol. 148, doc. 642. Y también F. SuÁrez BILBAO, Judíos castellanos entre 1432 y 1492 (Madrid 1990) vol. I pág. 48.

${ }^{46}$ Ladero "Préstamo" pág. 157, nota 26. En ese artículo se refleja que Mosé Tamaño es el mayor contribuyente de la aljama: aporta $40.000 \mathrm{mrs}$., el 30 por ciento de lo asignado al conjunto de los judíos de Ávila.

${ }^{47}$ AGS, RGS, 27-III-1480, fol. 251, doc. 3.039; también León Tello Avila págs. 22 y 150 . 
cios, a veces en colaboración con Mosé Tamaño o más frecuentemente con el converso bachiller Ruy López Beato. En 1487 ya había muerto y le sucede su hijo, también llamado Abraham Melamed, quien aparece en 1488 como recaudador "por sus Altezas" de las tercias de Ávila y su tierra ${ }^{48}$; éste probablemente fue quien se bautizó en junio de 1492 con el nombre de Tomás Núñez Coronel ${ }^{49}$. Y finalmente el rabí Yuçef Açamahas, casado con una hija del financiero segoviano don Abraham Seneor, del que sabemos que algún año arrendó las alcabalas y tercias de Cerrato y Candemuño; eran éstas unas rentas importantes pues la tercera parte de su cuarta parte se elevaba a $150.000 \mathrm{mrs}$. Este rabí también hacía préstamos a campesinos de la tierra de Ávila ${ }^{50}$. Como el resto de la familia de su suegro, se bautizó el 15 de junio de 1492 con el nombre de Alonso Pérez Coronel ${ }^{51}$.

A éstos habría que añadir Simuel Çerrulla, cirujano, quien en 1483 ya había muerto; su viuda Mioro continuaba con el negocio, de forma que en el préstamo de 1483 sería gravada con $28.000 \mathrm{mrs}$. E incluso podría incluirse en esta nómina de judíos potentados al corredor Yuçaf Çerrulla, hermano del anterior, quien aportó en el referido préstamo 9.000 mrs.; ambas cantidades eran la segunda y tercera más elevadas, respectivamente ${ }^{52}$.

Resulta significativo que en esta época los negociantes de la judería abulense, incluidos los más ricos, sólo raramente desarrollaran sus actividades dinerarias fuera del ámbito del distrito de Ávila ${ }^{53}$. En esto se diferenciaban netamente de sus correli544.

AHPAv, Prot. 420, fol. 297v; cf. Jiménez y Redondo Catálogo vol. II pág.

${ }^{49} \mathrm{Cf}$. infra nota 54 .

${ }^{50}$ Véase M. ${ }^{a}$ A. VArona, "Pleitos de judíos en la Real Chancillería de Valladolid: Regesta de sus cartas ejecutorias (1486-1495)", Sefarad 54 (1994) págs. 155-193, doc. 94.

51 Véase C. CARrete, «R. Abraham Seneor (Fernán Pérez Coronel): conjeturas tradicionales y realidad documental", Sefarad 46 (1986) págs. 111-121.

52 LAdero “Préstamo" pág. 156.

${ }_{53}$ En otros tiempos Ávila había proporcionado dos importantes figuras del mundo financiero y político judío: a finales del siglo XIII Yuçaf de Ávila fue uno de los principales arrendadores de impuestos del rey Sancho IV (BAER Historia vol. I pág. 160) y más tarde el maestre Semaya Bechacho, médico de Enrique IV, rab y juez mayor de los judíos de Castilla, elaboró el repartimiento del servicio y medio servicio del año 1464 (AGS, Escribanía Mayor de Rentas, leg. 13; apud LADERo "Juderías de Castilla" págs. 249-264). Este maestre Semaya (o Samaya) era experto en ginecología, por lo que atendió a la reina Juana de Portugal, deseosa 
gionarios de la vecina Segovia; y ello a pesar de determinadas relaciones de parentesco que había entre unos y otros ${ }^{54}$. Es probable que en esta relativa modestia y en la ausencia de ambiciones mayores se fundamente la paz social de que gozó la aljama de Ávila. Como los judíos castellanos desde hacía algún tiempo, y probablemente desde siempre, estaban acostumbrados a cambiar de lugar de residencia, aquella "paz abulense" no podía sino provocar la atracción de judíos procedentes de otros lugares menos tranquilos. De esta forma no es extraño que esta aljama terminara convirtiéndose en una de las comunidades judías más numerosas del país ${ }^{55}$.

Aparte de las anteriores, la mayoría de las personas agrupadas en el subsector de las finanzas aparece en los protocolos

de dar descendencia a Enrique IV; cf. L. SuÁrez Fernández, La expulsión de los judíos de España (Madrid 1991) pág. 246. También aparece documentado en 1451 recibiendo favores del rey Juan II; en ese momento es vecino de Ávila (LEÓN Tello Ávila pág. 136), pero en la década siguiente ya vive en Segovia, donde alcanzó el cénit de su influencia social. Hacia 1460 los judíos segovianos no estaban satisfechos con el poder que Enrique IV le había otorgado sobre ellos y se quejaron al contador real, Diego Arias Dávila (un judeoconverso también originario de Ávila), el cual logró que la aljama se reconciliara con maestre Semaya. En los círculos judíos de Segovia se le atribuía el envenenamiento de fray Alonso de Espina, quien en 1461 había escrito el difundidísimo libro Fortalicium fidei, donde se recogían y magnificaban todas las calumnias y leyendas que en adelante se atribuirían a los hebreos; cf. C. CArrete, Proceso inquisitorial contra los Arias Dávila: Un enfrentamiento social entre judios y conversos, vol. III de la serie Fontes Iudaeorum Regni Castellae (Salamanca 1986) págs. 43-44; y SuÁREz Expulsión págs. 247-251.

${ }^{54}$ Acabamos de ver cómo el rabí Yuçef Açamahas era yerno de don Abraham Seneor. Mayr Melamed, el otro gran financiero segoviano y a su vez también yerno de A. Seneor, procedía de Ávila: su padre y su madre eran originarios, respectivamente, de la ciudad de Ávila y de Cebreros. El apellido Melamed no era frecuente, de forma que es lógico suponer que el Abraham Melamed abulense tuviera vínculos familiares con Mayr Melamed. Por otra parte, al bautizarse el 15 de junio de 1492 diversos individuos de la familia Melamed tomaron el apellido Núñez Coronel; así está documentado en el caso de los de Segovia y Zamora; cf. C. Carrete "Seneor" y también M. A. Ladero Quesada, "Apuntes para la historia de los judíos y los conversos de Zamora en la Edad Media (siglos XIII-XV)", Sefarad 48 (1988) págs. 29-57. Pues bien, en Ávila aparece en 1500 un tal Tomás Núñez Coronel (uno así llamado vive en Alcalá de Henares en 1494; vid. AGS, RGS, 31-VII-1494, fol. 80), que era a la vez prestamista y mayordomo del Consejo, empleo éste que sólo era confiado a quien fuera conocido por la burguesía abulense por su solvencia y habilidad financiera: creo no arriesgar mucho si afirmo que este Tomás Núñez Coronel es el mismo que antes era conocido como Abraham Melamed, vecino de Ávila.

${ }^{55}$ Una justificación similar encuentra LADERo "Apuntes" pág. 40 para explicar el gran incremento demográfico de la aljama de Zamora a partir de 1485. 
notariales haciendo pequeños préstamos, casi siempre a campesinos del entorno ${ }^{56}$, y arrendando rentas o impuestos menores.

Aunque los judíos no eran los únicos que se dedicaban a estas actividades, no cabe duda de que en el ámbito del pequeño y mediano crédito desempeñaban un papel fundamental. Hay un episodio que lo confirma. En 1476, con ocasión de la aplicación de las Leyes de Madrigal, con las que se pretendió poner orden en las condiciones con que se efectuaban los préstamos entre particulares, se produjo un importante conflicto en Ávila. Estas leyes establecían que para poder cobrar lo que habían prestado, los judíos tenían que presentar dos testigos cristianos; como tal requisito era difícil de cumplir, los dirigentes de la aljama de Ávila decidieron que los judíos se negaran a prestar dinero en adelante tanto a "caballeros, como dueñas, como çibdadanos, como labradores" cristianos, amenazando con "echar descomunión" a quien no cumpliera la orden ${ }^{57}$. Dada la general escasez de liquidez propia de la época y los frecuentes pedidos reales, para cuya satisfacción se requería de numerario, el Concejo de Ávila interviene en la "huelga financiera" alegando que "dello se recresce gran daño e pérdida e agravio a esta çibdad e su tie-

56 Además de la información directa proporcionada por los escasos protocolos notariales conservados, hay un testimonio que corrobora que los clientes más asiduos de los prestamistas judíos eran los labradores: en 1502 regresaron de Portugal bautizados algunos judíos de Ávila y reclamaron los préstamos que no habían podido cobrar antes de salir del reino. Pues bien, los únicos que protestaron, a través del Procurador de los pueblos y sexmos de la tierra, fueron los campesinos (AHPAv, Ayunt. caja 2, leg. 158, publ. por León Tello Ávila págs. 113-114).

57 AAA-H, caja 1, leg. 49 (4-IV-1476). Si hemos de creer al corregidor de la ciudad, Juan Flórez, esta inicial firmeza de los judíos fue forzada por el "rico e hazendado" (así se le califica en una disposición real, AGS, RGS, 13-XII-1479, fol. 68, doc. 2.173) Mosé Tamaño, el cual "pone grandes miedos a las aljamas de los judíos e moros, faziéndolos poner escomunyón entre sí" (AGS, RGS, 4-XI-1479, fol. 114, doc. 2.064). Este personaje tenía buenas relaciones con la Corte: ya vimos cómo la reina le había nombrado juez mayor de la aljama de Ávila; además se indica que el miembro del Consejo Real enviado por Isabel I para investigar la actuación del corregidor se ha hospedado en casa del judío. Tal posición de privilegio le indujo a cometer algunos abusos urbanísticos en la propia judería, provocando la queja de otro correligionario, quien dice que "con la mucha fasyenda que el dicho Mosé Tamaño tiene, no pueden alcançar con él complimiento de justicia e ninguno osa embargar la dicha obra ni la osa reclamar" (AGS, RGS, marzo 1486, fol. 64, publ. por León Tello Ávila págs. 76-77). 
rra" ${ }^{58}$. En septiembre de 1479 y después de un proceso muy largo y complicado, la reina Isabel terminará dando la razón a los judíos ${ }^{59}$.

Los testimonios documentales referidos a los rabinos y sus funciones son mucho más escasos que los de prestamistas y arrendadores de rentas. Los 11 rabíes que había en Ávila en 1483 suponían un número considerable para una comunidad que no llegaba a las 300 familias. Tampoco eran escasas las sinagogas; hasta 1482 están documentadas al menos tres de ellas: la de Bilforad, la del Lomo y la de Moçón ${ }^{60}$. A partir de que los judíos fueran "retraídos e apartados", tuvieron que abandonarlas por estar fuera de las zonas asignadas como judería. En los años finales del siglo sólo hubo dos sinagogas, una "cabe la puerta que disen de la Malaventura" y la de la judería vieja ${ }^{61}$.

La abundancia de rabinos y de sinagogas hace pensar que se trataba de una comunidad bastante piadosa, de forma que no hay que extrañarse de que, llegado el momento de escoger entre conservar la fe o quedarse en su tierra, casi todos prefirieran marchar al exilio.

Otra profesión típica de los judíos, la de los médicos, cuenta con tres representantes ( 2 médicos y 1 cirujano), lo que no está nada mal si se tiene en cuenta que a mediados del siglo siguiente, para casi el doble de población, la ciudad de Ávila tendrá 5 médicos y 4 cirujanos ${ }^{62}$, lo que la situaba en buen lugar dentro de lo que era habitual en las ciudades castellanas de la época ${ }^{63}$.

Dado que no se conoce la existencia en Ávila de ningún otro médico o cirujano, ni cristiano ni musulmán, por los años a que nos estamos refiriendo, se puede afirmar que también en esta ciudad la profesión médica era monopolizada por los judíos. No

58 AAA-H, caja 1, leg. 49 (4-IV-1476).

59 AGS, RGS, 20-IV-1480, fol. 80, doc. 3.521. También SUÁREZ Expulsión págs. 282-284.

${ }^{60}$ LeÓn Tello Ávila págs. 125-126. Sobre el confuso asunto de la ubicación de las sinagogas de Ávila véase Belmonte Judios págs. 107-111, y M. Ayúcar, "Dos sinagogas y un descendiente de conversos", El Diario de Ávila 9 y 10 (nov. 1990) pág. 16

${ }^{61}$ León Tello Avila pág. 161.

62 "Padrón de la Averiguación de Alcabalas de 1561" (AGS, Exped. de Hacienda, leg. 50, apud TAPIA Comunidad morisca págs. 113-114).

${ }^{63}$ L. SÁnchez Granjel, La medicina española renacentista (Salamanca 1980) pág. 64. 
obstante, es probable que el momento de máximo esplendor de la medicina judía abulense tuviera lugar dos o tres décadas antes, cuando el maestre Semaya era médico personal del rey, cuando el cirujano Abraham Çerrulla era alcalde examinador de los físicos, cirujanos, especieros y boticarios de Ávila ${ }^{64}$, o cuando rabí Yuçé Cohén y rabí Mayr eran físicos del cabildo catedralicio ${ }^{65}$. La situación económica de estos profesionales era seguramente desahogada, pues es frecuente verlos realizando todo tipo de operaciones financieras.

Dos carniceros, imprescindibles para suministrar la carne kašer o legalmente apta para su consumo, una pescadera, un librero y un procurador de causas completan la nómina conocida de quienes componían el sector terciario.

Subrayo lo de conocida pues las fuentes conservadas son escasas. Hay un tipo de actividad que sorprendentemente no aparece desarrollada por nadie: la comercial. Y ello a pesar de la existencia de testimonios que expresamente dicen que "las personas que más tratan en lo susodicho [comprar e vender pannos e lanas] son los dichos judíos e moros" ${ }^{66}$, y que "el trabto e conversación de la dicha cibdad está en moros e judíos» ${ }^{67}$. Es más, ante la orden dictada por "las justicias" (los representantes de la Corona en la ciudad) de que los no cristianos tuvieran prohibida la venta de diversos productos alimenticios (pescado, sardinas, miel, aceite "ni otras cosas de comer") al conjunto de la población, las autoridades municipales protestan alegando que la "çibdad e veçinos e moradores della reçiben grand agravio e danno e no fallan las cosas que han menester para su proveymiento" ${ }^{68}$. Los Reyes ordenarán que esta prohibición se anule.

\section{Agricultura y ganadería}

Por lo que se refiere al sector primario no está documentado ni un solo judío en estas labores. Conviene recordar a este respecto lo que más arriba se dijo: que determinadas profesiones tienen tendencia a aparecer poco en la documentación notarial.

\footnotetext{
${ }^{64}$ AHPAv, Prot. 460, fol. 168v, apud Jiménez y Redondo Catálogo pág. 385.

${ }^{65}$ LeÓn Tello Ávila págs. 138-142.

66 AHPAv, Ayunt. caja 1, leg. 47 (1-XI-1480); publ. por LeÓN Tello Avila págs. $68-70$.

${ }^{67}$ AGS, RGS, 28-V-1488, fol. 8; publ. por León Tello Ávila pág. 79.

${ }^{68}$ Ibid.
} 
Resulta significativo que cuando se ha analizado, para fechas algo posteriores y con fuentes más explícitas, la estructura ocupacional de los moriscos (año 1503) y del conjunto de la población pechera de la ciudad (año 1517), resulta que la presencia de agricultores y ganaderos se limita al $3,4 \%$ y al $5,3 \%$ respectivamente de los efectivos totales ${ }^{69}$. La explicación radica en que el entorno de la ciudad es muy poco favorable para el aprovechamiento agrario.

Cuadro 2

Relación entre participación fiscal y tipo de profesión

\begin{tabular}{|c|c|c|}
\hline $\begin{array}{l}\text { Agrupación } \\
\text { profesional } \\
\end{array}$ & $\begin{array}{c}\text { Profesiones } \\
\text { incluidas } \\
\end{array}$ & $\begin{array}{c}\text { Promedio de mara- } \\
\text { vedís aportados } \\
\end{array}$ \\
\hline Financieros & $\begin{array}{l}\text { prestamista } \\
\text { corredor }\end{array}$ & $\begin{array}{r}34.000 \\
5.200\end{array}$ \\
\hline $\begin{array}{l}\text { Artesanos dueños } \\
\text { de talleres }\end{array}$ & $\begin{array}{l}\text { tintorero } \\
\text { tundidor } \\
\text { cerero } \\
\text { curtidor }\end{array}$ & $\begin{array}{l}2.200 \\
1.300 \\
1.200 \\
1.020\end{array}$ \\
\hline $\begin{array}{l}\text { Profesionales } \\
\text { liberales }\end{array}$ & $\begin{array}{l}\text { físico (médico) } \\
\text { cirujano } \\
\text { procurador } \\
\quad \text { de causas }\end{array}$ & $\begin{array}{r}1.450 \\
600 \\
600\end{array}$ \\
\hline $\begin{array}{l}\text { Artesanos dependien- } \\
\text { tes o asalariados }\end{array}$ & $\begin{array}{l}\text { cardero } \\
\text { jubetero } \\
\text { odrero } \\
\text { sastre }\end{array}$ & $\begin{array}{l}500 \\
400 \\
400 \\
375\end{array}$ \\
\hline
\end{tabular}

Relacionando las personas del listado publicado por Ladero Quesada con aquellas del nuestro de las que conocemos su ocupación, encontramos que son 23 los casos en que se sabe tanto el oficio como la cantidad aportada en el préstamo de 1483. Con el fin de comprobar si la cuantía asignada a cada individuo guarda relación con la riqueza que se supone a los diversos tipos de oficio, he elaborado cuatro agrupaciones profesionales. Los resultados expresados en el Cuadro 2 parecen tener cierta lógica. Tal como ya observó Ladero Quesada, sólo unas pocas personas contribuían con cantidades elevadas. Si excluyéramos a los tres

69 Véanse mis trabajos Comunidad morisca pág. 181 y «Estructura ocupacional de Ávila en el siglo XVI", en El pasado histórico de Castilla y León (Burgos 1983) vol. II págs. 201-223. 
financieros que hicieron aportaciones sobresalientes (de 40.000, 28.000 y 9.000 mrs., respectivamente), restan 53.000 mrs., lo cual supone una media de $791 \mathrm{mrs}$. por persona ${ }^{70}$. Comparando con esta cifra las aportaciones de las diversas profesiones, se observará quiénes podrían incluirse en el grupo de los relativamente acomodados y quiénes en el de los menudos.

\section{ESPECIALIZACIÓN PROFESIONAL Y COMPLEMENTARIEDAD ÉTNICA}

Como conclusión del análisis de las profesiones de nuestra minoría, creo que puede ser interesante comparar entre sí las estructuras ocupacionales de cada una de las tres naciones que componían la población de la ciudad de Ávila. Aunque no ha sido posible encontrar fuentes adecuadas para hacer coincidir en el mismo año tales datos, la corta distancia existente en cada uno de los cortes cronológicos propuestos creo que permite establecer comparaciones aceptables. En todo caso, es preciso considerar estos datos con cierta cautela, tal como más arriba se dijo y como para cristianos viejos y para moriscos he dejado escrito en otros trabajos ${ }^{71}$.

Los datos del Cuadro 1 permiten deducir que, en líneas generales, cada uno de los grupos étnicos se había especializado en determinados subsectores productivos. Así, los judíos tenían predilección por las labores del cuero, las finanzas y la sastrería. Los moriscos casi monopolizaban el transporte y el pequeño comercio así como la artesanía del metal. Por su parte, los cristianos viejos, mucho más numerosos, estaban más homogéneamente repartidos entre todos los subsectores, aunque su presencia en la manufactura textil es relevante ${ }^{72}$, lo mismo que en la confección y en el cuero/calzado; claro está que en estos dos últimos subsectores resultaba imprescindible un número considerable de artesanos cristianos-viejos, tanto por tratarse de labores que en todas las ciudades de la época ocupaban altos

${ }^{70}$ Los 791 mrs. no eran una cantidad insignificante. Por aquellos años el jornal de un carpintero abulense era de $25 \mathrm{mrs}$. (AHPAv, Prot. 421, fol. 217v [20-I-1477]), es decir, que aquella cantidad significaba el sueldo de 31 días de trabajo.

71 Véase nota 69.

72 Si bien todavía en 1517 dicha presencia está muy lejos de la preponderancia que alcanzará en el último tercio del siglo; concretamente en 1590 este subsector ocupará a 314 cabezas de familia, lo que supone el 21,5 por cien de los activos (AHPAv, Ayunt. caja 68, leg. 12/14). 
porcentajes del artesanado, como por cubrir el hueco dejado por los judíos (recuérdese que son datos referidos a 1517).

Igualmente significativo puede ser el desinterés de cada uno de los grupos étnicos por determinados trabajos; desinterés que suele corresponder con la especialización en esas labores de otra de las naciones. Así ocurre con la construcción/carpintería y el comercio/transporte, frecuentes entre los musulmanes y olvidados por los judíos, y a la inversa con la sastrería y las finanzas, preferidas por judíos e ignoradas por los mudéjares. Los judíos tienen casi nula presencia entre el servicio doméstico y el artesanado artístico, ámbitos cubiertos por los cristianos; en cambio éstos - no hay que olvidar que sólo estamos considerando a los pecheros- no se dedican a las actividades financieras, al contrario de lo que ocurre con los judíos.

Dado que, como vimos más arriba, el volumen demográfico de los dos grupos minoritarios no era meramente simbólico sino que alcanzaba un nivel importante, incrementado por su laboriosidad, se puede afirmar que existía una clara complementariedad o distribución de labores entre cristianos, judíos y musulmanes, lo cual redundaría no sólo en un incremento de la eficacia profesional, como corresponde a toda especialización, sino en el fortalecimiento de la conciencia colectiva de que cada una de las etnias hacía una aportación fundamental para el correcto funcionamiento de la vida urbana ${ }^{73}$.

$\mathrm{Y}$ aquí puede estar el fundamento del alto grado de tranquilidad que rigió las relaciones interétnicas en Ávila lo cual, a su

\footnotetext{
${ }^{73}$ Un buen ejemplo de este reparto de funciones es el que regulaba el uso y mantenimiento del principal elemento arquitectónico y urbanístico de Ávila, las murallas. En 1481 surgió un problema respecto a qué tipo de obligaciones tenían cristianos, judíos y moros en la defensa del alcázar y, por extensión, de las murallas. En el curso del debate suscitado el alcaide de la fortaleza dice, sin que nadie le contradiga, que "los vezynos e moradores de la dicha çibdad e su tierra tenían desde tienpo inmemorial a esta parte rrepartidos en esta manera: que los caualleros e fijos dalgo en los tienpos que la dicha çibdad se auía de velar e se velava heran obligados a la rrondar e que ansy la rrondauan e que los omes buenos e çibdadanos heran obligados a la velar e los vezinos e vasallos de la tierra de la dicha çibdad auían sido obligados a rreparar los adarues e las cannas de la dicha çibdad e traer todos los materiales que heran neçesarios de piedra e cal e arena para los dichos muros e que los moros de la dicha çibdad auían sydo e heran obligados a poner las manos e los judíos el fierro" (AAA-H, caja 1, leg. 69). El que los judíos aportasen el hierro que se necesitaba para las cadenas del puente levadizo y otros elementos de cerrajería vendría determinado porque este material había que comprarlo en las ferrerías vascas pagando en metálico su coste, y eran ellos los que más capacidad de liquidez económica tenían en aquellos momentos de penuria monetaria.
} 
vez, provocaría la atracción hacia esta ciudad de quienes huían de ambientes más tensos. Los propios judios eran conscientes de que su presencia en la ciudad era apreciada y por ello en 1480 , en el marco del conflicto que les enfrentó con los cristianos viejos por el asunto de los préstamos usurarios, no dudan en amenazar con irse "de la dicha çibdad a bevir a otras partes". Los Reyes Católicos accederán a sus peticiones "porque la dicha çibdad se non despueble» ${ }^{74}$.

\section{DifERENCIACIÓN SOCIAL INTERNA}

Aparte de la preeminencia social de los rabíes, fundamentada en factores religiosos y jurídicos, hemos de suponer que también entre los judíos el factor económico hubo de provocar el surgimiento de una cierta diferenciación social en el seno de la aljama. Efectivamente, esta hipótesis parece quedar corroborada por nuestras fuentes.

Si se analiza el status social de las cinco personas que ocuparon cargos públicos en la comunidad judía, vemos que dos de ellos, don Abrahem Sevillano y don Isaque Bechacho, se dedican a las finanzas -actividad propia de gentes adineradas- y otros dos, don Abrahem Gago y don Isaque Cohén, aunque ignoramos su profesión, aportaron en el préstamo de 1483 cantidades muy superiores a la media. Excluidos los tres financieros con aportaciones excepcionales, dicha aportación media fue de 791 mrs., en tanto que ellos pagaron 1.400 y 2.100 mrs., respectivamente. Del último de los personajes, el procurador don Salamón Fari, carecemos de datos profesionales o económicos. Por tanto, no es arriesgado suponer que había una tendencia a encomendar las funciones de representación de la aljama a individuos económicamente solventes ${ }^{75}$.

El segundo tipo de información al que se puede acudir es el empleo del tratamiento de don o de doña. Aunque algunos autores sostienen que su uso no supone ningún matiz social, la

${ }^{74}$ AGS, RGS, 20-V-1480, fol. 80, doc. 3.531 (véase también supra nota 58).

75 También el acaudalado hombre de negocios Isaque Tamaño recibió en 1476 poder de la aljama para intervenir en los asuntos de la Hermandad y para hacer cualquier repartimiento (AHPAv, Prot. 421, fol. 102v). Ya dijimos que inexplicablemente este poderoso personaje no fue incluido en nuestro listado (véase supra y notas 19 y $44-45$ ). 
mayoría cree, y yo con ellos, lo contrario; significativamente las citadas cinco personas con cargos en la aljama recibían todas el título de don. En nuestra lista lo ostentan 55 varones $(22,3 \%)$ y una mujer.

Al comparar dicha lista con la del préstamo publicado por Ladero hallo que coinciden 65 hombres y 2 mujeres. De esos 65 hombres, 26 usan el don en nuestra fuente ( $40 \%$ ) siendo gravados, y esto es lo relevante, con una media de 2.777 mrs.; mientras que quienes no usan el don aportan $725 \mathrm{mrs}$. como promedio. En esto tampoco se diferenciaba la comunidad judía abulense de la de otros lugares ${ }^{76}$.

\section{ONOMÁSTICA MASCULINA}

Es habitual en este tipo de listados proceder al análisis de los nombres empleados que en ellos aparecen. Los 239 varones de los que conocemos su nombre propio utilizan 33 nombres diferentes; es muy frecuente que un mismo nombre presente diversas grafías a causa de la variabilidad de la onomástica medieval y en ocasiones debido a corrupción gráfica derivada del desconocimiento del hebreo por parte de los escribanos cristianos, que son quienes redactaron la documentación que estamos empleando. Aunque pueda parecer que existía una aceptable diversidad en la antroponimia, hay que decir que la mayor parte de la población ostenta sólo unos pocos de esos 33 nombres; concretamente los 6 nombres más frecuentes afectan al 61,4 por cien de los varones (Cuadro 3).

Me ha parecido interesante establecer una comparación en esta cuestión con el comportamiento onomástico de los cristianos viejos y de los musulmanes abulenses coetáneos. Entre los 844 cristianos viejos pecheros de 1502 los 6 nombres más habituales (Juan, Pedro, Alonso, Diego, Francisco y Cristóbal) afectan al 63,9 del conjunto; de los 424 musulmanes de los que a lo largo del siglo XV nos consta su nombre, los 6 nombres preferidos (Alí, Mahomad, Yuçafe, Abraham, Hamad y Abdalla) suponen el 67,5 por cien ${ }^{77}$. Estos datos nos permiten establecer que el

${ }^{76}$ Véase, por ejemplo, el caso de Torrelaguna: E. Cantera Montenegro, "Judíos y conversos en Torrelaguna (Madrid) en tiempos de la expulsión", en Estudios en memoria del Prof. D.- Salvador de Moxó (Madrid 1982) págs. 233-252.

77 Véanse las referencias documentales en mi libro Comunidad morisca págs. $86-91$ y $141-143$. 
uso de un escaso abanico de nombres masculinos judíos respondía a las costumbres generales del momento más que a una peculiaridad de esa comunidad. Incluso se comprueba que en ésta existía una variación algo mayor a la de los otros grupos.

He aquí los 33 nombres de los 239 varones de nuestro listado, por orden de frecuencia, con indicación del número total y de las diferentes grafías y el número parcial de éstas (uso como encabezamiento la forma más frecuente; entre paréntesis se añade al final la transcripción de la grafía hebrea normativa):

Ysaque 33 (Isaq 1, Çag 1, Ça 1) = 36 (hb. Yiş̧ ac)

Yuçef 21 (Yuçaf 3, Yuçá 2, Yuçefe 1, Yuçé 1, Yuçafe 1) $=29$ (hb. Yosef)

Mosé 24 (hb. Mošé)

Abraham 15 (Abrahán 5, Abrahem 2) $=22$ (hb. Abraham)

Simuel 18 (hb. Šemuel)

Salamón 14 (Çulemán 4) $=18$ (hb. Šelomó)

Jacó 14 (hb. Ya áacob)

Sentó 10 (hb. Šem Tob)

Çaçón 9 (hb. Sasón)

Yudá 8 (hb. Yehudá)

Daví 6 (hb. David)

Hayn 4 (Ayn 1) $=5$ (hb. Hayim); vid. también Vital

Ximón 4 (Simón 1$)=5(\mathrm{hb}$. Šimón $)$

Barú 4 (hb. Baruj)

Menahem 3 (hb. Menahem)

Nehoray 2 (Neoray 1$)=3$ (hb. Nehoray)

Binanmín 1 (Binnamín 1, Benanmín 1) $=3$ (hb. Binyamín)

Yentó 3 (hb. Yom Tob)

Leví 2 (hb. Leví)

Licio 2 (Eliseo ?)

Mayr 2 (hb. Meir)

Velloçid 2

Abib 1 (hb. Habib)

Azecrí 1

Çahadiá 1 (hb. Sa ádiá)

Çidbueno 1

Farache 1

Hesrá 1 (hb. Ezrá)

Hiel 1 (hb. Yehiel)

Sisa 1

Usiel 1 (hb. Uziel)

Vidal 1 (forma romance de hb. Hayim)

Yoel 1 (hb. Yoel) 


\section{Cuadro 3}

Nombres de los judios de Ávila (1483)

\begin{tabular}{|c|c|c|c|}
\hline & número* & porcentaje & $\begin{array}{l}\text { porcentaje } \\
\text { acumulado }\end{array}$ \\
\hline Ysaque (etc.) & 36 & 15 & 15 \\
\hline Yuçef (etc.) & 29 & 12,1 & 27,1 \\
\hline Mosé & 24 & 10 & 37,1 \\
\hline Abraham & 22 & 9,2 & 46,3 \\
\hline Simuel & 18 & 7,5 & 53,8 \\
\hline Salamón (etc.) & 18 & 7,5 & 61,3 \\
\hline Jacó & 14 & 5,8 & 67,1 \\
\hline Sentó & 10 & 4,2 & 71,4 \\
\hline Çaçón & 9 & 3,8 & 75,1 \\
\hline Yudá & 8 & 3,3 & 78,4 \\
\hline Daví & 6 & 2,5 & 80,9 \\
\hline Hayn (etc.) & 5 & 2,1 & 83 \\
\hline Ximón (etc.) & 5 & 2,1 & 85,1 \\
\hline Barú & 4 & 1,7 & 86,8 \\
\hline Menahem & 3 & 1,2 & 88 \\
\hline Nehoray & 3 & 1,2 & 89,2 \\
\hline Binnamín (etc.) & 3 & 1,2 & 90,2 \\
\hline Yentó & 3 & 1,2 & 91,4 \\
\hline Leví & 2 & 0,8 & 92,2 \\
\hline Licio & 2 & 0,8 & 93 \\
\hline Mayr & 2 & 0,8 & 93,8 \\
\hline Velloçid & 2 & 0,8 & 94,6 \\
\hline Abib & 1 & & \\
\hline Azecrí & 1 & & \\
\hline Çahadiá & 1 & & \\
\hline Çidbueno & 1 & & \\
\hline Farache & 1 & & \\
\hline Hesrá & 1 & & \\
\hline Hiel & 1 & & \\
\hline Sisa & 1 & & \\
\hline Uçiel & 1 & & \\
\hline Vidal & 1 & & \\
\hline Yoel & 1 & & \\
\hline Total & 239 & 100 & \\
\hline
\end{tabular}




\section{LOS NOMBRES DE LAS MUJERES}

La sociedad de la época concedía poco peso social público a las mujeres y esto se refleja en la documentación conservada. Ya vimos cómo sólo 18 mujeres aparecían en el listado de 1483, de las cuales únicamente dos de ellas (Mioro y doña Vellida) aparecen con su propio nombre. Las otras 16 son denominadas por el nombre de su marido, incluso aunque estuvieran viudas, con la expresión "La de ...", uso que era común para las tres etnias ${ }^{78}$.

Con el concurso de otras fuentes he logrado conocer el nombre de tres de esas viudas (Hasy Buena, Reina y Lidicia), así como el de otras 21 mujeres que tienen vínculos familiares con alguno de los varones del listado. He aquí la relación de todos los nombres, con indicación del año al que corresponde la información y la referencia documental:

Açiba, esposa de Daví Melamed; 1477 (LT $307^{79}$ ).

Aljoar (cf. aljófar 'perla'), viuda de Abrahem Melamed, el viejo, y madre de Abraham Melamed, el joven; 1487 (LT 371) ${ }^{80}$.

Clara (doña), e sposa de don Simuel Gago; 1464 (LT 244).

Clara (doña), esposa de don Çaçó Masod; 1474 (LT 295).

Çidbuena, madre de Nehoray Çerrulla; 1471 (LT 281).

Dona (doña), esposa de don Yuçaf Çerrulla, corredor; 1477 (LT 304).

Dona (doña), esposa de don Mosé Tamaño; 1469 (LT 273).

Fandueña, hermana de don Simuel Gago; 1470 (LT 275).

Fermosa, esposa de Ça Negrita; $1450^{81}$.

Franca, mujer de Jacó Negrita; 1477 (LT 306).

Hasy Buena (doña), viuda de don Sentó Abenhabid, procurador de la aljama; 1455 (LT 215).

Ledicia, esposa de Isaque Chuclel; 1488 (LT 388).

Lidicia (doña), madre de rabí Yuçef Açahamas y viuda de Salamón Açahamas; $1491^{82}$.

\footnotetext{
${ }^{78}$ Véase nota anterior.

${ }^{79}$ Uso LT para referirme a LEÓN TELLO Ávila, seguido del número de documento en su Inventario.

${ }^{80}$ En Zaragoza está documentada una judía llamada Aliofar, año 1406; vid. A. BLAsco, "Instituciones sociorreligiosas judías de Zaragoza (siglos XIV-XV): Sinagogas, cofradías, hospitales», Sefarad 50 (1990) págs. 3-46: pág. 43.

81 Jiménez y Redondo Catálogo vol. I doc. 1.097.

82 Arch. Real Chancillería de Valladolid, Pergaminos, caja 37, $\mathrm{n}^{\circ} 31$, apud VARONA "Pleitos" pág. 179.
} 
Lima, esposa de Jacó Loçano, cirujano; 1477 (LT 304).

Lumbre, esposa de Isaque Daça; 1482 (LT 346 y 349)

Masaltón (hb. Mazal Tob), esposa de Mosé Tibona; 1475 (LT 297).

Mioro (doña), viuda de maestre Simuel Çerrulla, cirujano; 1463 y 1492 (LT 241 y 450).

Oroçeti, esposa de Licio Ferrero; 1492 (LT 444).

Plita (doña), esposa de Yudá Siao, físico; 1477 (LT 306).

Rael (doña; hb. Raḥel), esposa de Leví, albardero; 1480 (LT 335).

Reina (doña), la [viuda ?] de Isaque Honén; 1480 (LT 336).

Soloro la chapinera (doña), madre de Mosé chapinero; 1483 (LT 353 y 345$)^{83}$.

Urusol (doña), esposa de rabí Çulemán Daça y madre de Çidbueno Daça; 1492 (LT 451).

Urusol (doña), esposa de Yuçef Açeror; 1474 (LT 1474).

Vellida (doña), viuda de Mosé Daça; 1483 (LT 358).

Vellida (doña), esposa de don Yoel Açamahas; 1488 (LT 398).

Son, por tanto, 26 mujeres con 21 nombres diferentes. Sólo cinco nombres (Clara, Dona, Ledicia/Lidicia, Urusol y Vellida) se repiten una vez. Es sorprendente esta gran variedad onomástica que contrasta con lo que se ha visto en el caso de los hombres. De todas formas, con un número tan reducido de personas es imprudente proponer cualquier tipo de hipótesis explicativa de este fenómeno. También es digno de subrayar la abundancia relativa de nombres de origen romance (Dona, Vellida, Reina, Fermosa, Franca, Lumbre, etc.), frente a sólo dos formas de nombres hebreos (Masaltón y Rael). En todo caso, este elenco por corto que sea viene a enriquecer nuestros magros conocimientos de la onomástica femenina del judaísmo medieval español ${ }^{84}$.

${ }^{83} \mathrm{Ni}$ madre ni hijo aparecen en mi relación fiscal de 1483 ; o al menos no les identifico bajo esta denominación. Sin embargo en un códice de la catedral aparece una tal Soloro viviendo entre 1481 y 1483 en la calle Pescadería (apud León Tello Ávila págs. 151 y 152).

${ }^{84}$ Sirva de comparación y de ejemplo la información aportada por dos de las listas más numerosas de sendas comunidades judías: ni un solo nombre femenino aparece entre los 115 judíos de Jaca en 1377 (Romano «Prorrata"); tres nombres proporciona el listado de 168 vecinos hebreos de Talavera de la Reina en 1477-1478 (C. CARRETE, "Talavera de la Reina y su comunidad judía: Notas críticas al padrón de 1477-1478", en En la España medieval: Estudios dedicados al Prof. Julio González González [Madrid 1980] vol. I págs. 43-57). 


\section{Conclusión}

En lo que se refiere al volumen demográfico, con estas páginas creo haber contribuido a que poco a poco se vayan sustituyendo las afirmaciones apriorísticas por los datos objetivos. Y éstos nos indican, por una parte, que en Ávila había menos población judía de lo que hasta ahora se pensaba; y por otra, que no obstante la anterior afirmación la comunidad hebrea abulense era muy posiblemente la más numerosa de la Corona de Castilla. Así pues, cabe concluir que estamos ante un nuevo argumento que refuerza la opinión de quienes piensan que hay que revisar a la baja el número total de los judíos españoles expulsados, al menos de aquellos de origen urbano.

Desde el punto de vista de la caracterización profesional de este grupo humano, se reafirma el predominio de los artesanos, especialmente los relacionados con el cuero y la confección textil, y se consolida la imagen de que las finanzas de la ciudad y su tierra (especialmente el pequeño y el mediano crédito) giraban en torno a determinados individuos judíos.

Quizá lo más significativo de este estudio sea haber puesto de manifiesto la existencia de una nítida especialización profesional de cada uno de los tres grupos étnicos presentes en la ciudad (judios, musulmanes y cristianos), especialización que llevó aparejada una cierta complementariedad entre ellos. Es muy probable que esta circunstancia, junto con la ausencia de especiales ambiciones políticas o económicas entre los individuos de los grupos minoritarios, fuera el factor que estabilizó las relaciones interétnicas en esta ciudad sirviendo de atractivo a determinados judíos castellanos que a lo largo del siglo habían ido buscando su asentamiento en Ávila.

El resultado de todo lo anterior fue que a finales del medievo esta era la ciudad de la Corona de Castilla donde el porcentaje de cristianos respecto al total de su población era menor; en ninguna otra convivieron tantos judíos y musulmanes con la mayoría cristiana y tan pacíficamente. Así pues, en cierta manera cabría reivindicar que el papel que a lo largo de los siglos XII al XIV desempeñó Toledo como ciudad de las tres culturas había pasado a la ciudad del Adaja, si bien resulta ineludible tener en cuenta que en la segunda mitad del siglo XV tanto la comunidad 
judía como la musulmana se habían visto privadas (los primeros por su conversión y los segundos por su huida a Granada) de gran parte de sus individuos más cultos y dinámicos.

En todo caso, el carácter emblemático de Ávila se ve reforzado; pero será preciso sustituir aquella imagen de ciudad galvanizada por un cristianismo belicoso y excluyente, sugerida por sus impresionantes murallas levantadas "contra los moros" y reforzada con los escritos del abulense C. Sánchez Albornoz, por la de ser la población que gracias a su tolerancia logró hasta el final un mejor aprovechamiento de la convivencia (sin duda no igualitaria) entre las tres naciones que a lo largo de la Edad Media contribuyeron a conformar la personalidad de nuestro país. 


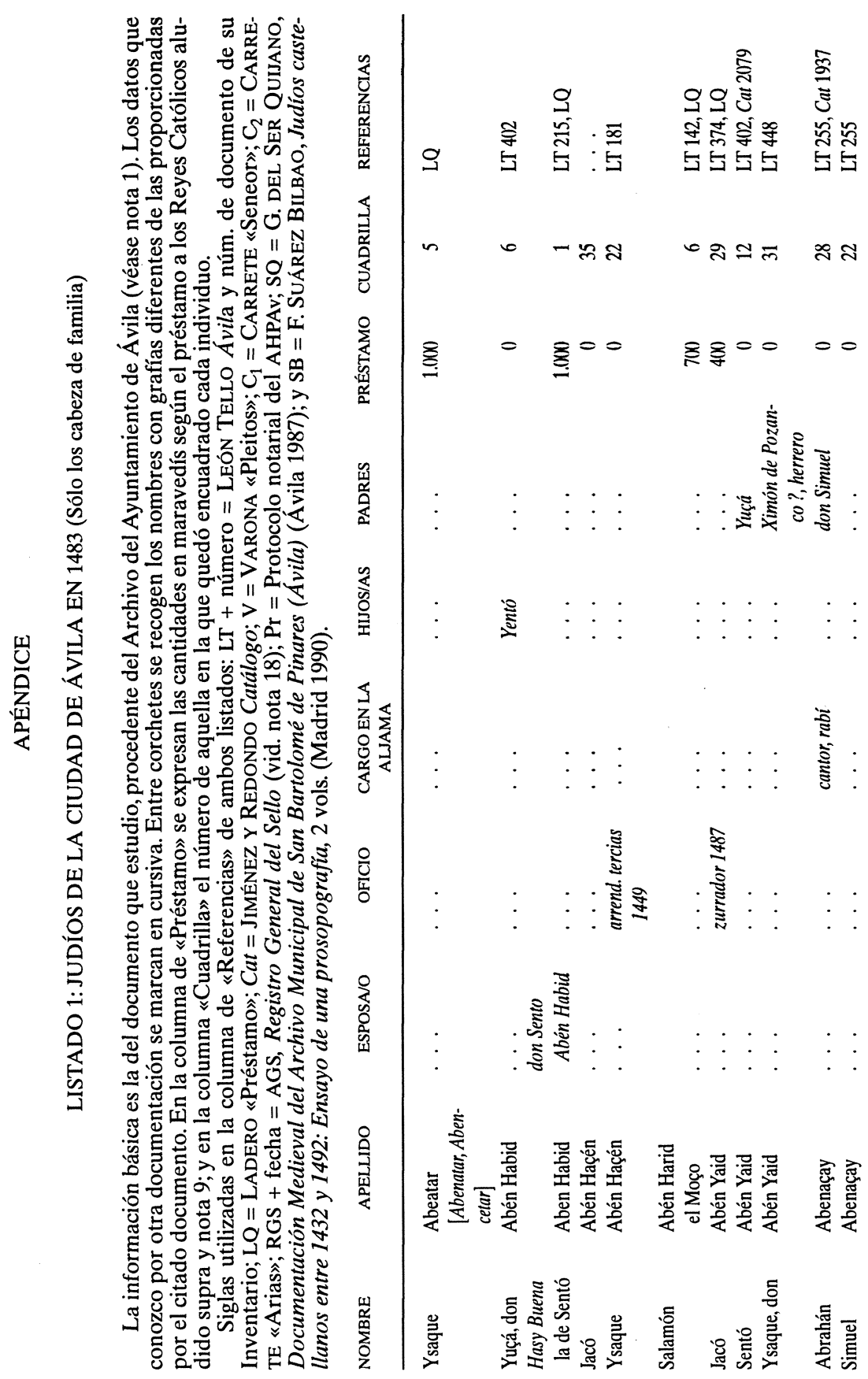




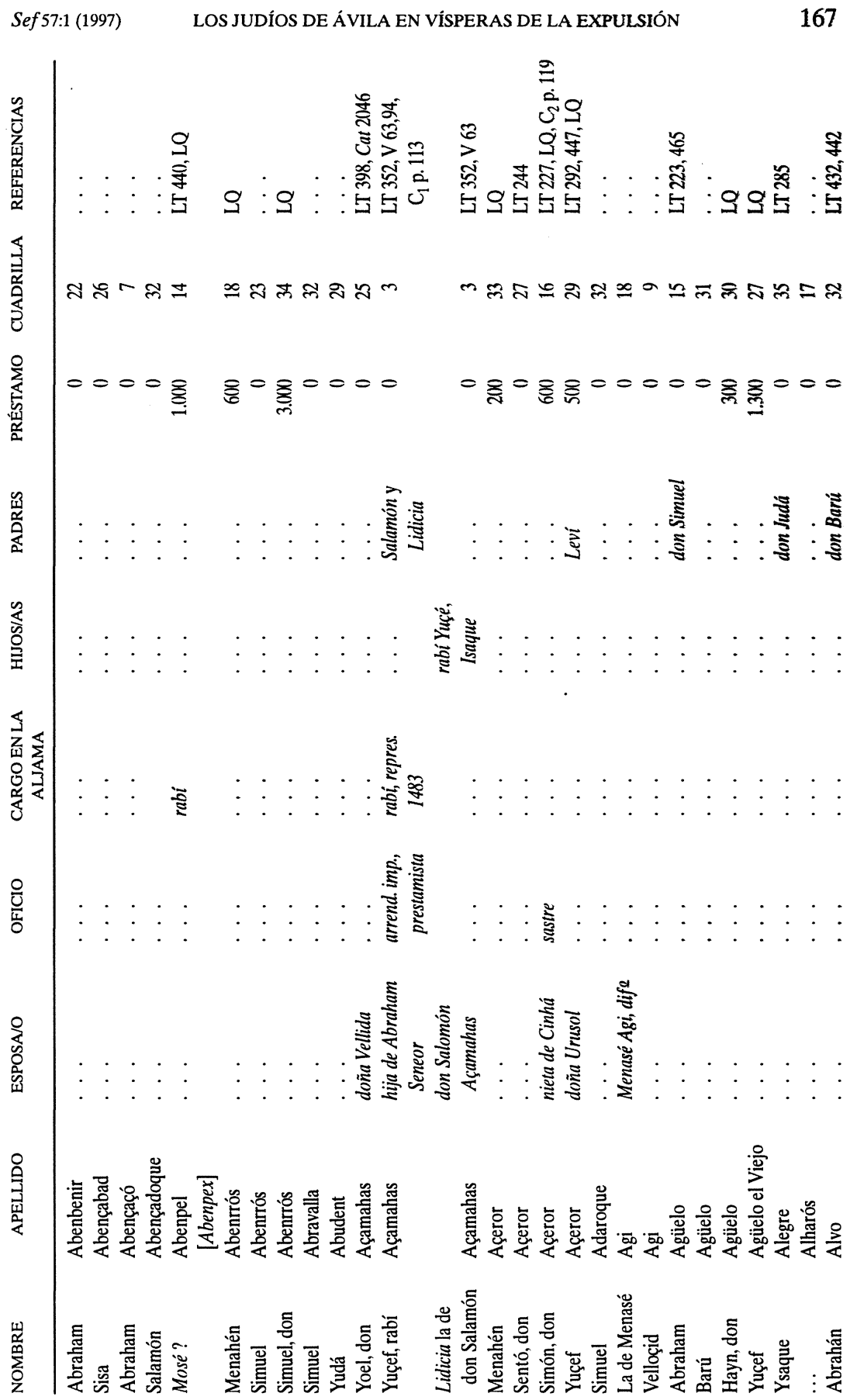




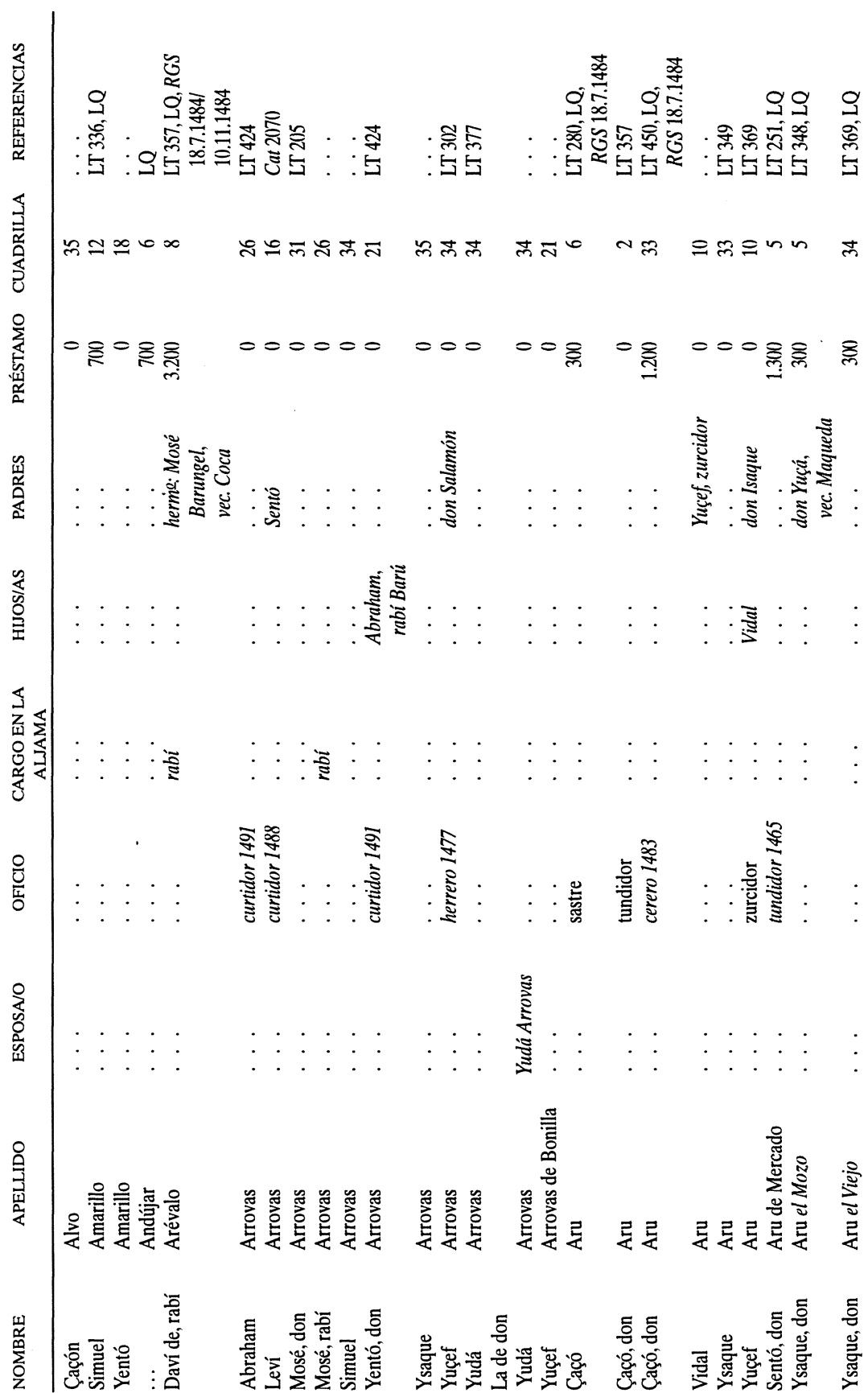




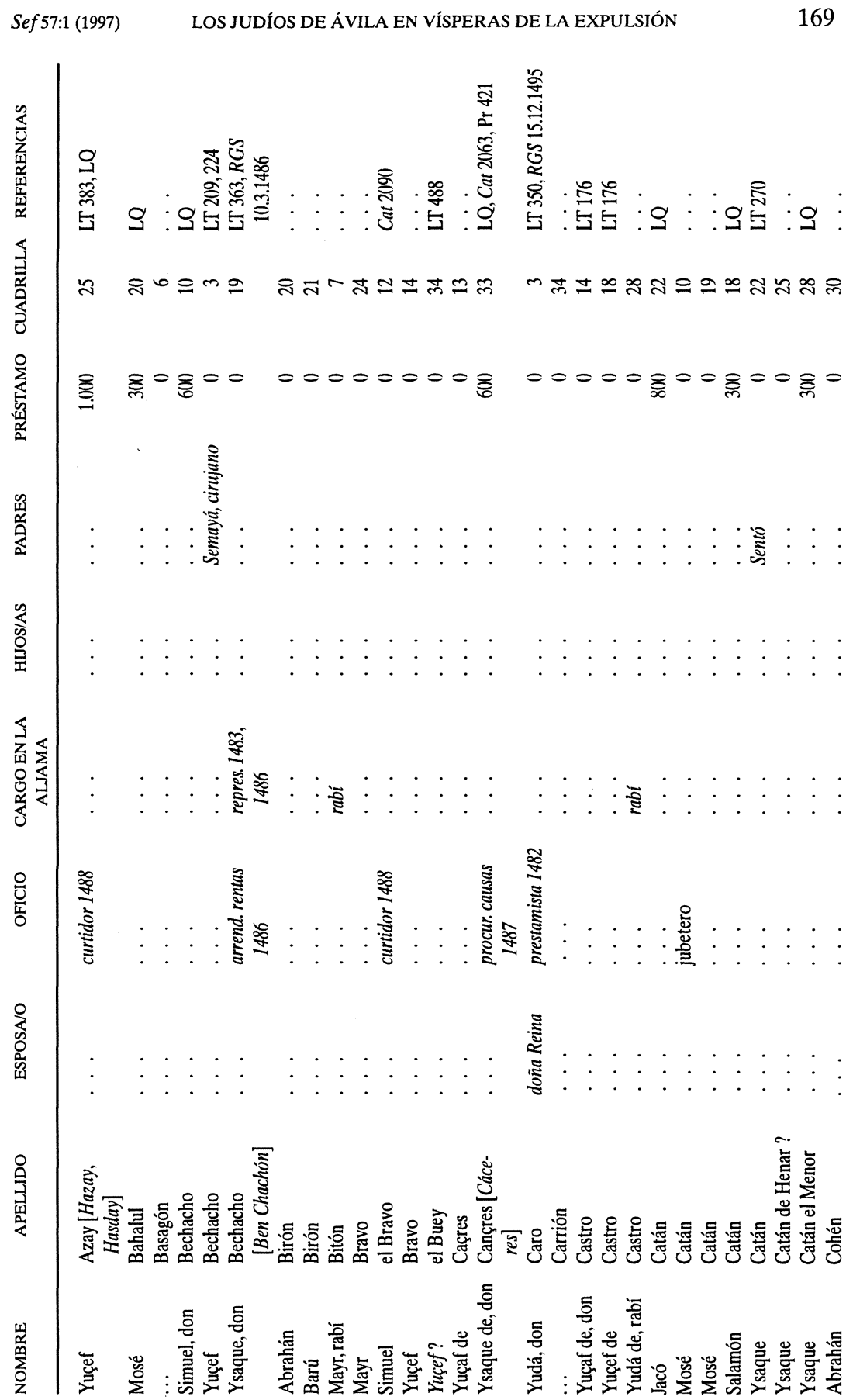




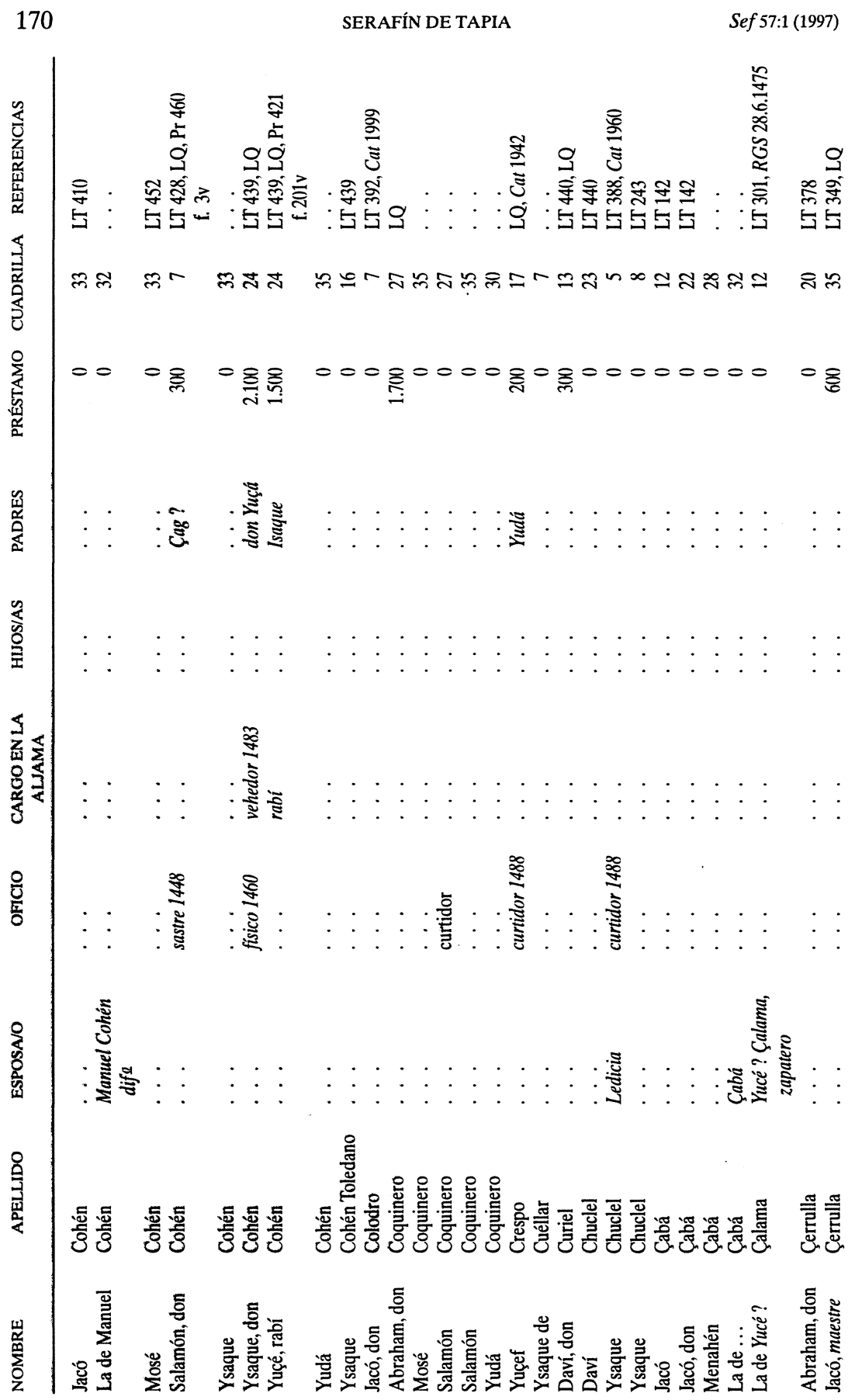




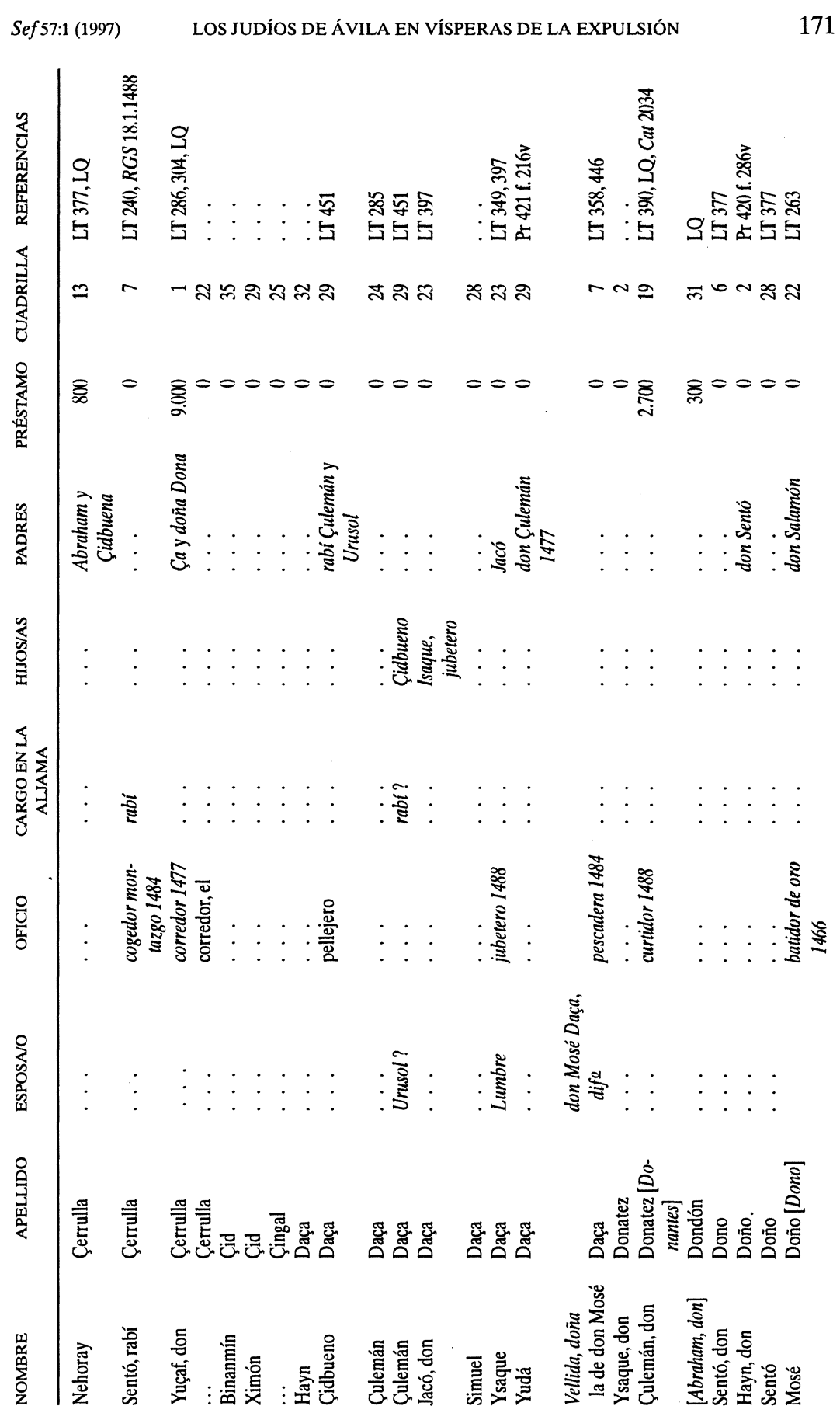




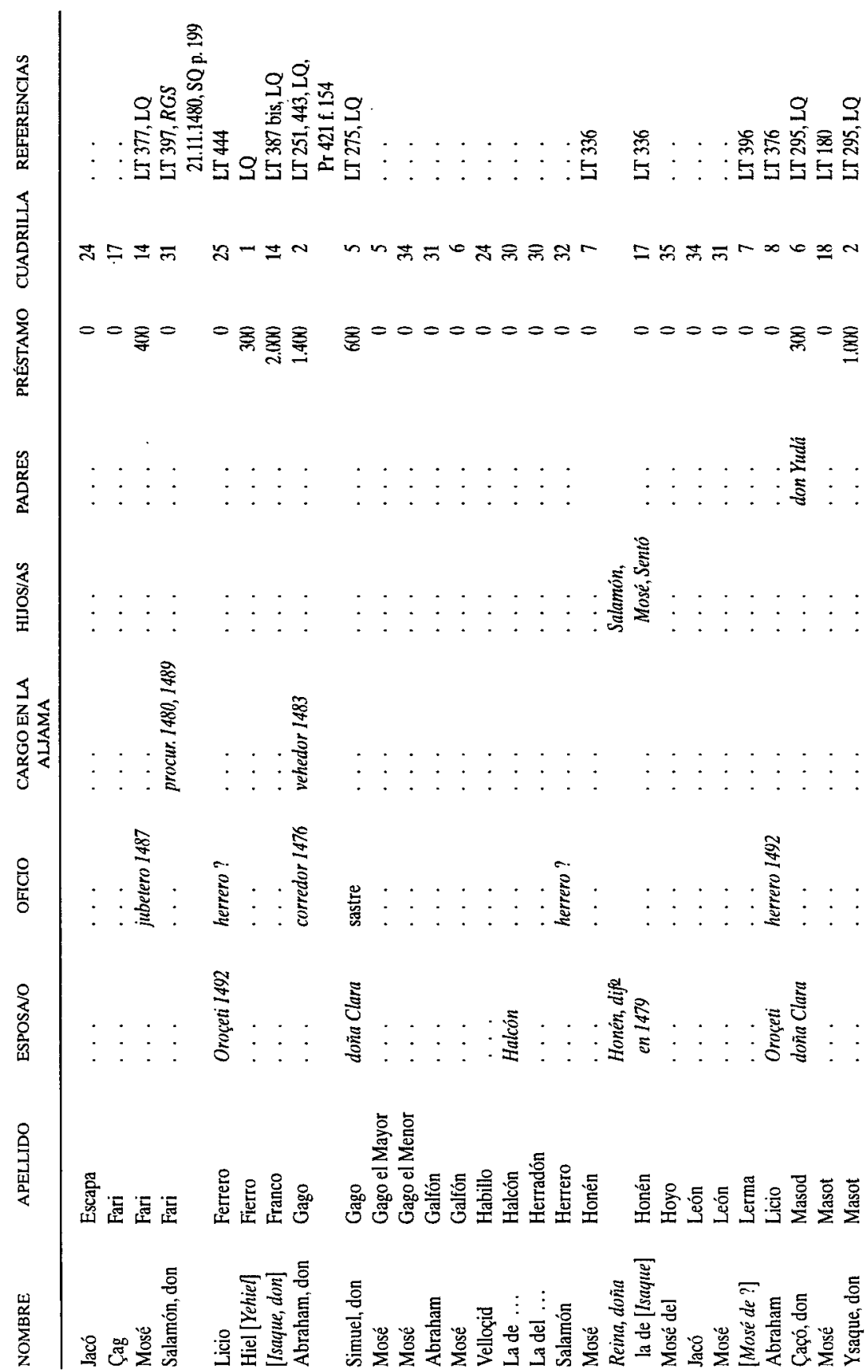




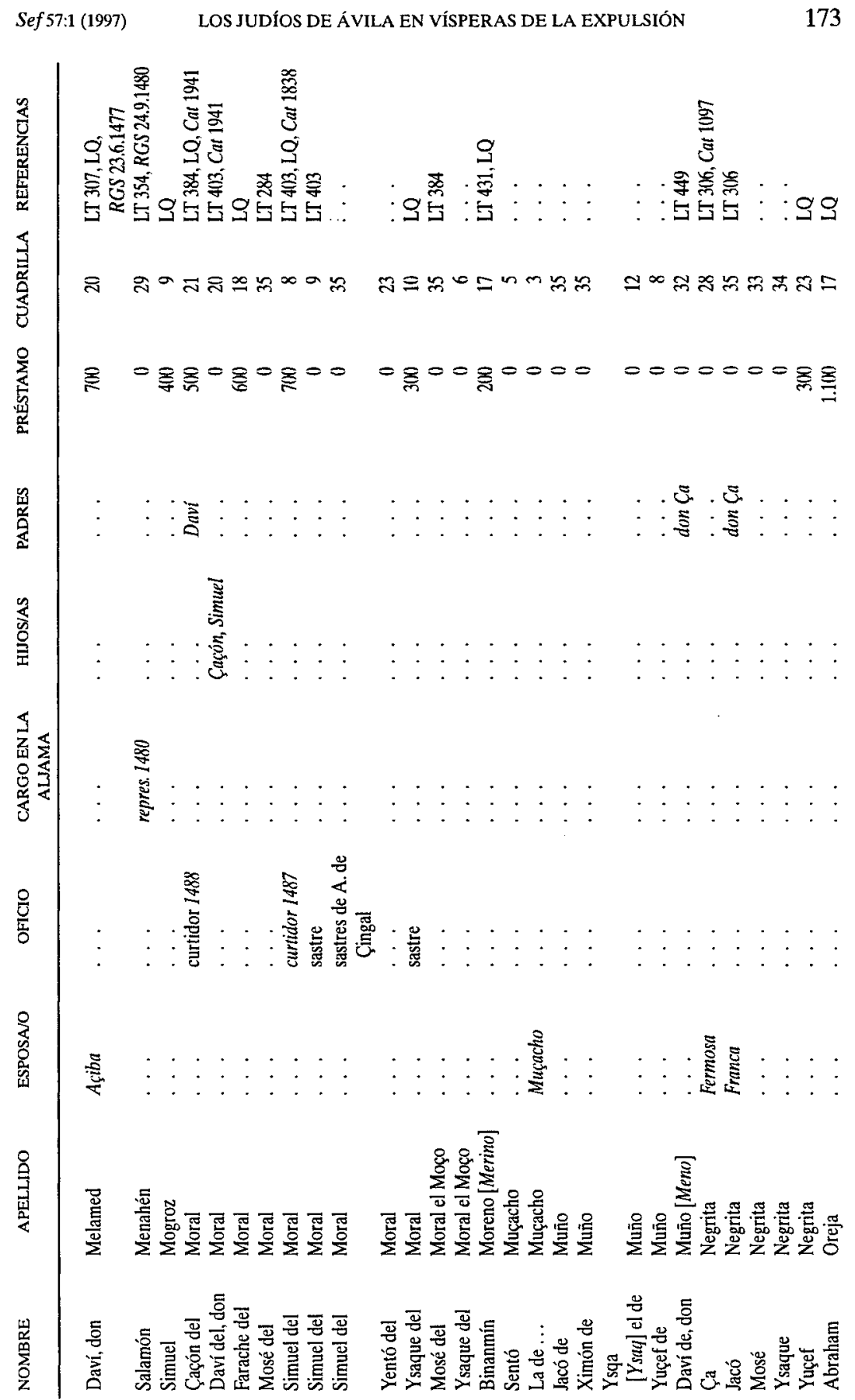




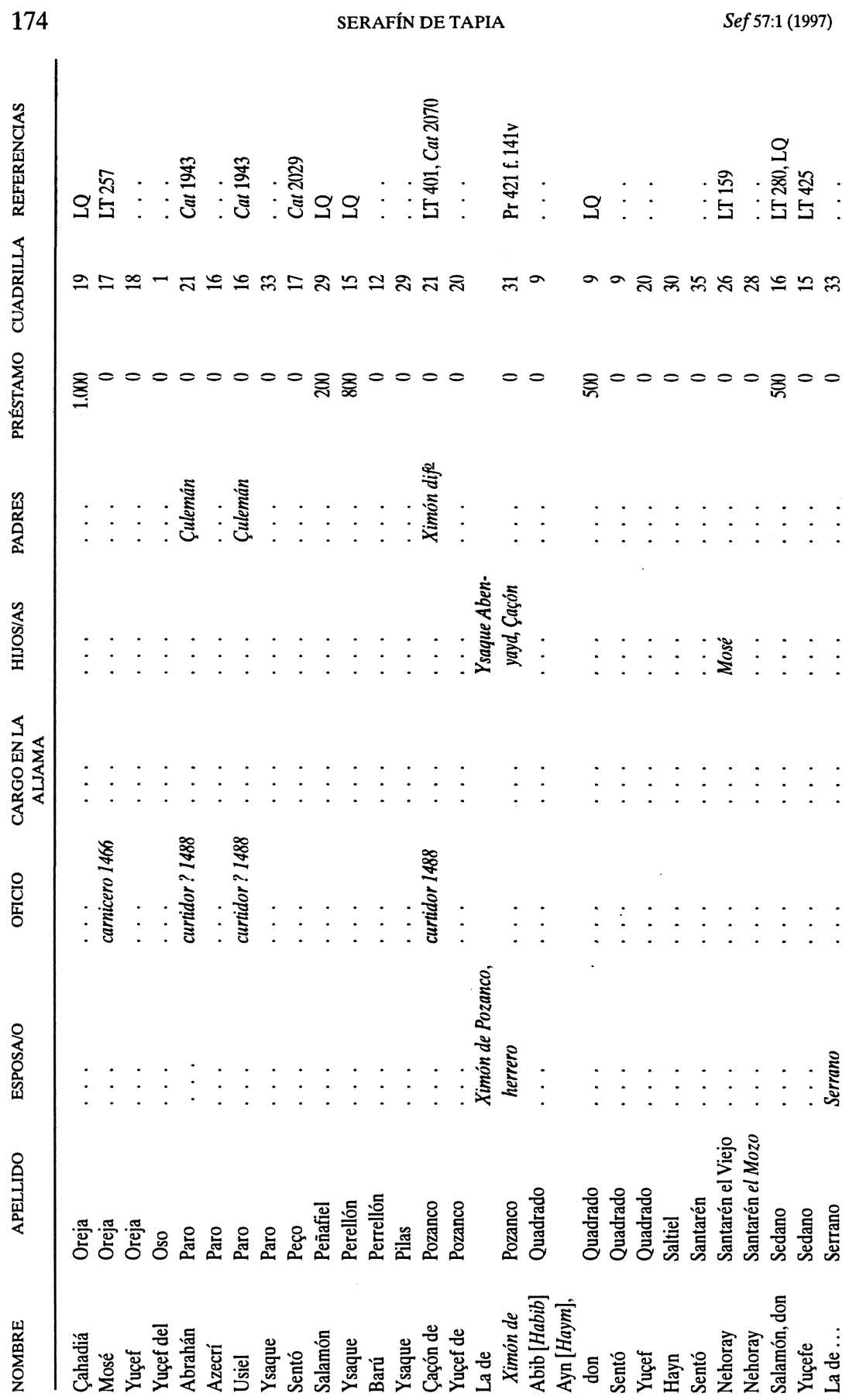




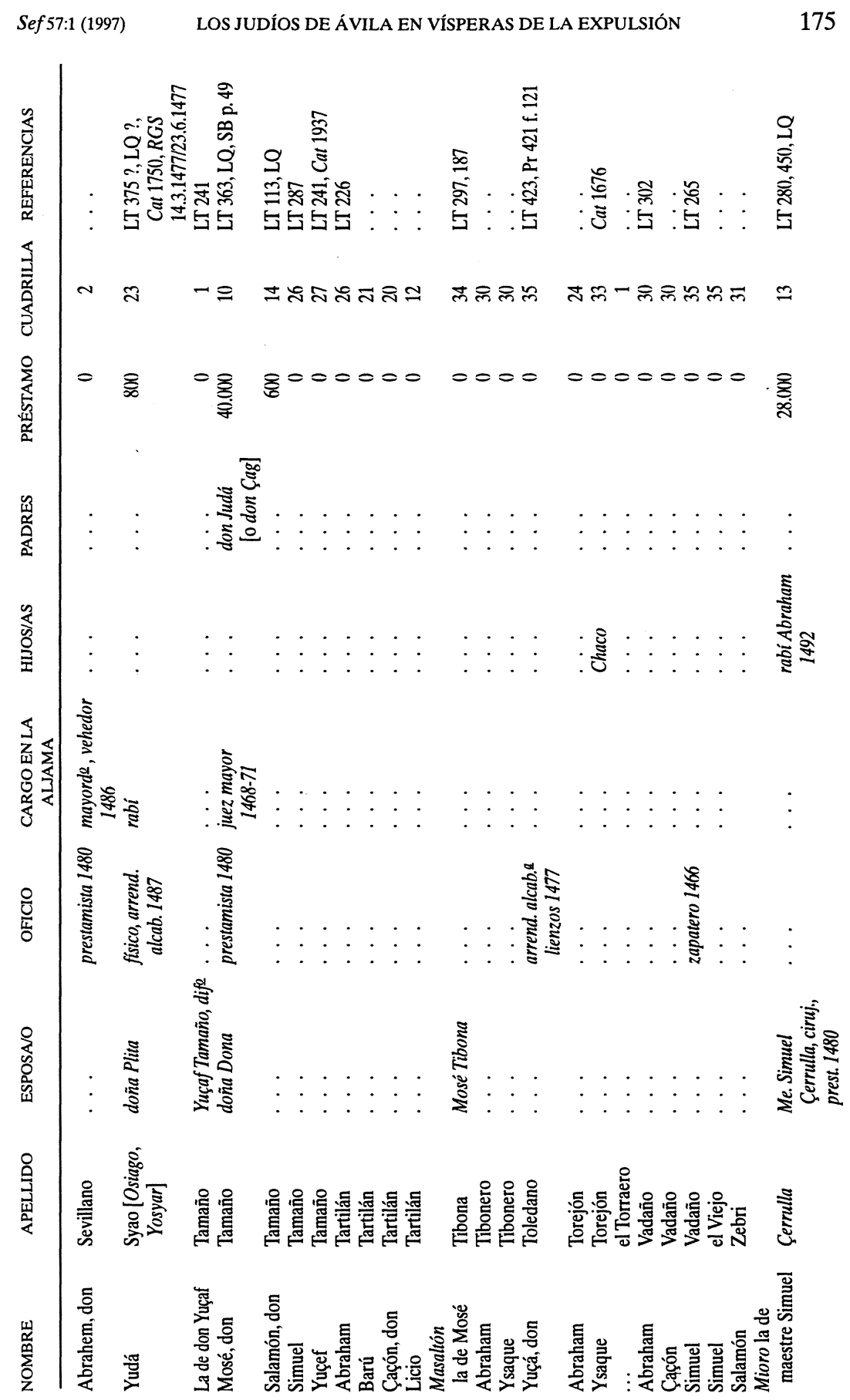




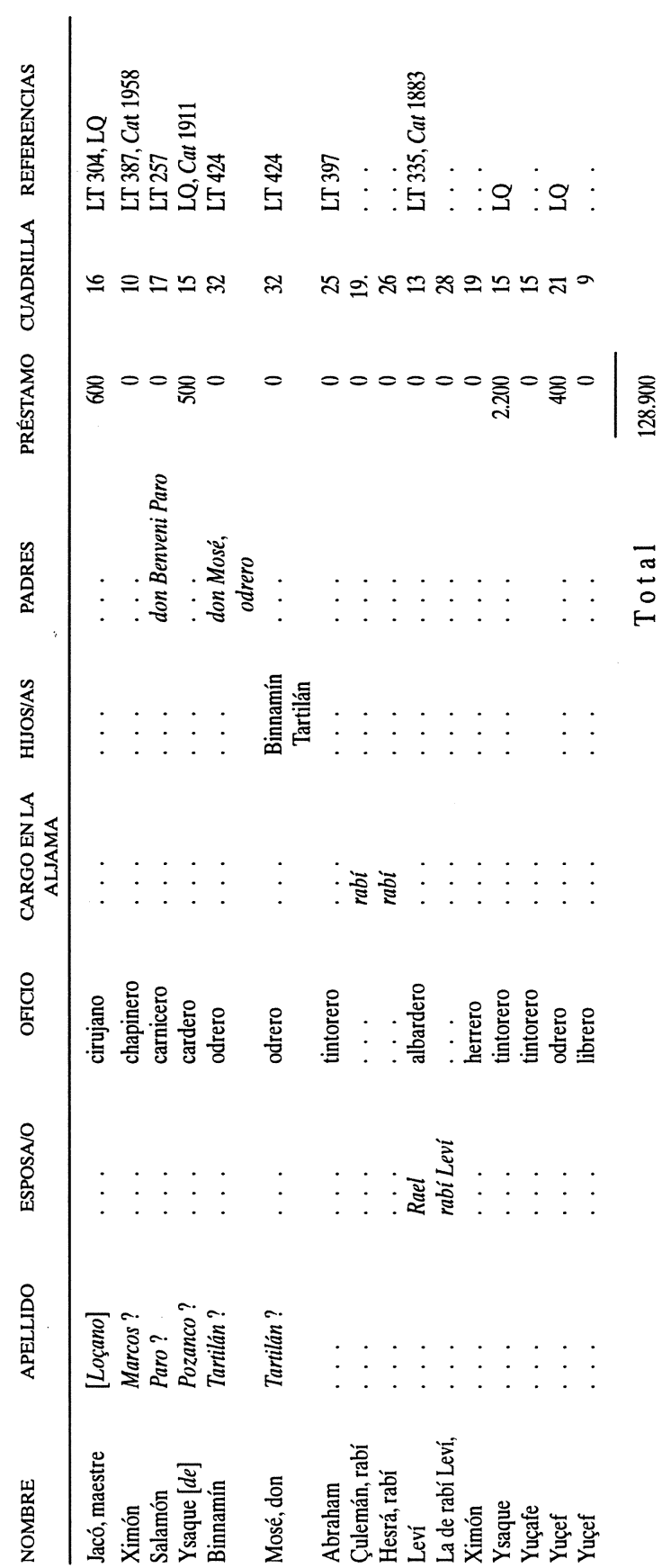




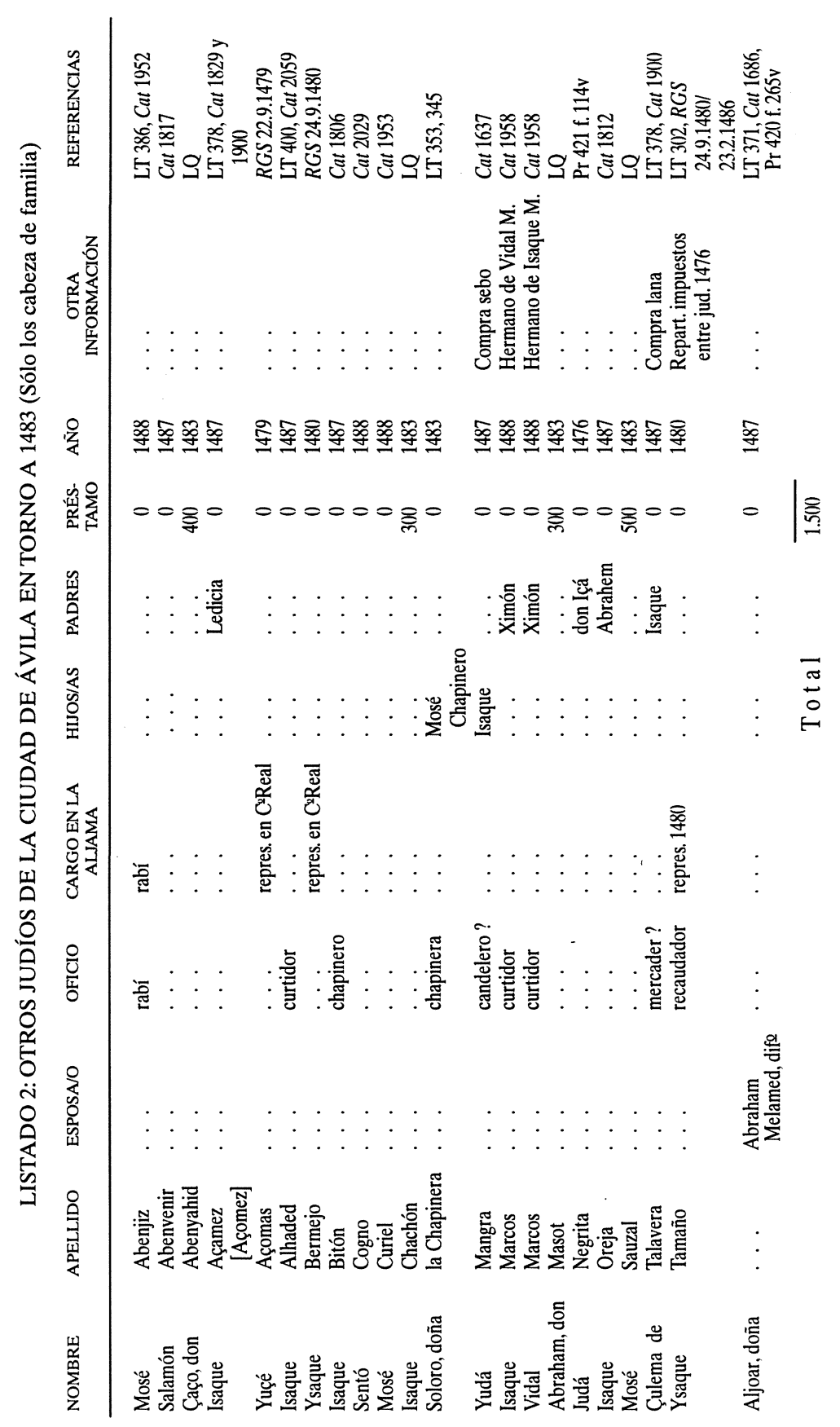




\section{RESUMEN}

A partir de la información proporcionada por un detallado padrón fiscal de 1483 , por los protocolos notariales de la época y por diversa documentación municipal, se desvelan diversos aspectos de la vida de los judíos de la ciudad de Ávila a finales del siglo XV: la discriminación fiscal, el volumen demográfico, la estructura ocupacional, el alto grado de complementariedad profesional existente entre los cristianos, los judíos y los musulmanes abulenses $\mathrm{y}$, por último, la onomástica masculina y femenina de este grupo humano. También se avanza una hipótesis para explicar por qué en esta ciudad se terminó juntando la comunidad judía más numerosa de la Corona de Castilla en las vísperas de su expulsión.

\section{SUMMARY}

From the information obtained from a detailed fiscal census dated 1483 , as well as from the notarial documents of the period and from various municipal documents, diverse aspects of the life of the Jews of the city of Ávila at the end of the 15th century are disclosed, namely fiscal discrimination, demographic ratio, professional structure, high level of professional distribution among the Christians, the Jews and the Muslims of Ávila, and the masculine and feminine first names of this group. A hypothesis is also advanced to explain why the most numerous Jewish community of the kingdom of Castile gathered together in Ávila on the eve of their expulsion. 